\title{
Revisiting the B-cell compartment in mouse and humans: more than one B-cell subset exists in the marginal zone and beyond
}

Olivier Garraud ${ }^{1,2,3,10^{*}}$, Gwenoline Borhis ${ }^{4,5,6}$, Gamal Badr ${ }^{7,8}$, Séverine Degrelle 4,5,6 , Bruno Pozzetto 1,9, Fabrice Cognasse $e^{1,2}$ and Yolande Richard ${ }^{4,5,6}$

\begin{abstract}
The immunological roles of B-cells are being revealed as increasingly complex by functions that are largely beyond their commitment to differentiate into plasma cells and produce antibodies, the key molecular protagonists of innate immunity, and also by their compartmentalisation, a more recently acknowledged property of this immune cell category. For decades, B-cells have been recognised by their expression of an immunoglobulin that serves the function of an antigen receptor, which mediates intracellular signalling assisted by companion molecules. As such, B-cells were considered simple in their functioning compared to the other major type of immune cell, the T-lymphocytes, which comprise conventional T-lymphocyte subsets with seminal roles in homeostasis and pathology, and non-conventional T-lymphocyte subsets for which increasing knowledge is accumulating. Since the discovery that the B-cell family included two distinct categories - the non-conventional, or extrafollicular, B1 cells, that have mainly been characterised in the mouse; and the conventional, or lymph node type, B2 cells — plus the detailed description of the main B-cell regulator, FcyRllb, and the function of CD40 antigen presenting cells as committed/memory B-cells, progress in B-cell physiology has been slower than in other areas of immunology. Cellular and molecular tools have enabled the revival of innate immunity by allowing almost all aspects of cellular immunology to be re-visited. As such, B-cells were found to express "Pathogen Recognition Receptors" such as TLRs, and use them in concert with B-cell signalling during innate and adaptive immunity. An era of B-cell phenotypic and functional analysis thus began that encompassed the study of B-cell microanatomy principally in the lymph nodes, spleen and mucosae. The novel discovery of the differential localisation of B-cells with distinct phenotypes and functions revealed the compartmentalisation of B-cells. This review thus aims to describe novel findings regarding the B-cell compartments found in the mouse as a model organism, and in human physiology and pathology. It must be emphasised that some differences are noticeable between the mouse and human systems, thus increasing the complexity of B-cell compartmentalisation. Special attention will be given to the (lymph node and spleen) marginal zones, which represent major crossroads for B-cell types and functions and a challenge for understanding better the role of B-cell specificities in innate and adaptive immunology.
\end{abstract}

Keywords: BCR, MZ, Breg, B-cells, TLR, Cytokines, Chemokines

\footnotetext{
* Correspondence: olivier.garraud@efs.sante.fr

'EA3064-GIMAP, Université de Lyon, Saint-Etienne, France

${ }^{2}$ EFS Auvergne-Loire, Saint-Etienne, France

Full list of author information is available at the end of the article
} 


\section{Review and conclusion Introduction}

A key property of B-cells is that these unique cells of the adaptive immunity branch are the only cells capable of editing epitope-specific tools, i.e., antibodies (Abs), by rapidly superimposing genetic events that end with somatic mutations and class switching to ensure extremely efficient immune responses to a panoply of pathogens, particularly T-dependent (TD) antigens (Ags). Although progress is still being made in understanding the intricate mechanisms of this extremely complex genetic event, this function of B-cells is considered their classical property. Evidence is growing that innate immunity is regaining the importance it probably lost when the much-sought-after function of adaptive immunity and the highly sophisticated role of conventional lymphocytes were finally understood. Intriguingly, while many cell subsets are specific to each branch of immunity, it is now apparent that B-cells have almost equivalent roles in either branch, and their importance as innate immune cells has now been recognised with the discovery of functional and tissue-specific subsets in bone marrow (BM), secondary lymphoid organs and mucosae. B-cells may behave as one-man-bands, using the most appropriate instrument (B-cell receptor, Toll-like receptors, cytokine/chemokine-receptors, etc.) for each situation, but they are also highly plastic in their capacity to produce cytokines. This property was only recently appropriately acknowledged, in comparison to the champion cells for polarising immune responses such as T-cells, dendritic cells (DCs) or macrophages (and now platelets). In hindsight, however, this property could have been deduced from one of the first descriptions of how a lymphocyte was reprogrammed, i.e., after infection with Epstein-Barr virus (EBV) through its unique receptor, CR2/CD21 [1]. Paradoxically, the rediscovery of the roles and functions of B-cell subsets in innate immunity provides the "non-classical" (new) part of the story, which itself is far from being complete, since many discrepancies between mouse and human systems plead for novel extensive research efforts to fill in the gaps.

\section{Arising questions on B-lymphocytes}

Decades ago, lymphocytes were discovered as the major tools of specific immunity, now defined as adaptive immunity, which has unique characteristics based on clonal differentiation and a repertoire of $\mathrm{Ag}$ recognition. A long-term paradigm then arose, which postulated that Bcells underwent terminal differentiation into plasma cells and that the majority were then confined to antibody (Ab) production, while some differentiated B-cells were spared from this terminal pathway to constitute a pool of memory B-cells. Memory as well as activated B-cells were then shown to efficiently present Ags to T-cells and undergo mutual activation/differentiation processes that involve cytokines and several pairs of co-stimulatory molecules, including the well-known CD40/CD40L pair [2]. The constitutive expression of CD40 was ascribed first to B-cells, and then extended to most Ag presenting cells (DC and macrophages); this property helped to decipher the Ag presenting cell (APC) function of activated/memory B-cells and their use alongside Major Histocompatibility or MHC molecules [3]. The co-expression of MHC and of CD40 does not, however, licence immune cells as APCs (e.g. platelets possess such characteristics) [4].

B-cells were essentially described for their indispensable role in the so-called humoral (Ab-based) immunity, and the machinery supporting their central functions was thought to be essentially located in the germinal centres (GCs) of lymph nodes and the spleen. Years later, it was acknowledged that this functional microanatomy also concerned the mucosal equivalents of lymph nodes, thus supporting mucosal immunity. With further investigation, however, it became evident that Bcells can exert a number of Ab-independent functions, including capturing and concentrating Ags for presentation, producing cytokines, influencing $\mathrm{T}$-cell and $\mathrm{DC}$ responses, contributing towards distinct functions during the immune response in vivo, affecting lymphoid tissue structures, and even participating in tissue repair [5].

Around fifteen years ago, the conceptual barrier between specific and non-specific immunity was breached and novel functions were ascribed to innate immunity. As such, the role of almost every immune cell type was revisited. There were few changes to some areas, e.g., conventional T-cells, but novel and important functions have been ascribed to non-conventional T-cells, NK-cells and NKT-cells. The issue of B-cells was much more intriguing for two main reasons: 1) the discovery/identification of non-conventional B-cells; and 2) the identification of nonself infectious danger sensors or receptors (Rcs), which are thought to characterize innate immunity and are abundantly-expressed on B-cells. Indeed, the concept of non-self-infectious danger was subsequently addressed [6], Pathogen Associated Molecular Patterns (PAMPs) were described on pathogens, and PAMP-counter ligands, namely Pathogen Recognition Receptors (PRRs), were identified on the sensing and sentinel cells of innate immunity. PRRs have remained extremely conserved throughout the evolution of living organisms, with a key family being the Toll-like Rcs or TLRs. We, and others, have further described that a specific pattern of TLRs characterizes every B-cell subset [7-10]. B-cells express Rcs for immunoglobulins (Ig) such as FcyRIIb/CD32 or FceRII (CD23). CD32 mediates inhibitory signals to BcR-activated B-cells, but also authorizes the internalisation of immune complexes. CD23 is essential for B-cell responses and distinguishes various immature and mature B-cell subsets. 
Complement Receptor 2 (CR2/CD21) is also found on $\mathrm{B}$-cells, where it amplifies BcR signalling through its association with CD19 and its downstream PI3K-dependent signalling pathway [11]. CD21 also constitutes the unique receptor for $\mathrm{EBV}$, a herpes virus responsible for infectious mononucleosis that is present in more than $85 \%$ of healthy individuals in its latent form. Reactivation of EBV is frequently observed in chronically HIV-infected patients where it correlates with a higher frequency of circulating transitional-like B-cells [12]. In addition, $\mathrm{EBV}^{+} \mathrm{B}$-cell lymphomas are more frequent in HIV-infected patients than in the general population [13].

The capacity of specific B-cell subsets to traffic throughout the body is essential for sampling pathogens, but also for their APC functions [14]. Accordingly, distinct programs of chemokine receptor expression were also ascribed to the various B-cell subsets [15]. Whereas most B-cells express CXCR4 and CXCR5 throughout the course of B-cell differentiation, their balanced expression is decisive for the emigration of immature B-cells from $\mathrm{BM}$ into the spleen where CXCL12, the ligand of CXCR4, is highly expressed in the red pulp [16]. In steady-state conditions, the homing of mature naïve Bcells into follicle anlagen is driven by strong expression of CXCL13, the ligand of CXCR5, within the white pulp [17], whereas the trafficking of memory B-cells beneath CCL20-expressing epithelia is orchestrated by CCR6 [18]. Other chemokine receptors, in association with the highly tissue-specific expression of their ligands, orchestrate B-cell homing into intestinal mucosa (CCR9, CCR10) or the skin (CCR4) in combination with integrins and other adhesion molecules $[16,19,20]$. BcR or CD40 signals and TLR agonists can tune the expression of chemokine receptors [18,21-23] and therefore impair their trafficking. As such, B-cells that were thought to be almost "rude" cells according to the classical T-cell/Bcell paradigm, are actually split into numerous subpopulations that are functionally and spatially distinct.

Even more recent observations indicate that marginal zone (MZ) and B1-like B-cells are engaged in the innate arm of immune defence [24,25], and that immunoglobulins (Igs) are comprised of two distinct molecular tools: 1) B-cell receptor/"specific" Abs; and 2) instruments of the innate immunity branch, the so-called "polyreactive Igs" that are largely associated with extrafollicular B1cells [26]. Besides MZ B-cells, recently defined B-cell subsets have also captured the attention, including regulatory B-cells and CD21 ${ }^{\text {lo }}$ B-cells. Although B-cell phenotype characteristics and physiological functions need to be better defined, recent studies in mice (and also in humans) have clearly revealed their distinguished roles in chronic infection, autoimmune disease and aging. This confirms that B-cells are not only actors but also key regulators in the immune response. This essay thus aims to revisit B-cell immune physiology and reconsider B-cells alongside more recent discoveries.

\section{Marginal zone B-cells perform a key role in microbial infection \\ The marginal zone: from structure to function}

Besides its crucial role in filtering the blood and recycling red blood cell components and iron, the spleen is also the largest secondary lymphoid organ of the body after the discontinuous gut-associated lymphoid tissue (GALT). Whereas the erythrocyte-rich "red pulp" leads to a functionally slow bloodstream that favours blood filtration, the organisation and functions of the lymphocyterich "white pulp" closely resemble those found in lymph nodes, with B-cell follicles and T-cell zones [27]. A highly specialised micro-anatomical site surrounding the white pulp, referred to as the MZ, constitutes a unique structure that allows interactions between the key effectors of innate and adaptive immunity.

The MZ is recognised as an anatomical site that enables the cells leaving the bloodstream to transit from the red to the white pulp. The MZ shows prominent structural variation in different animal species: it is well developed in rodents, intermediately developed in primates (human and non-human), and poorly developed in the dog and cat [28]. Whereas the white pulp is specialised for adaptive responses (including Ab-based responses to TD Ags), the MZ is more specialised for the response to blood-borne pathogens (bacteria and viruses), and in particular to T-independent (TI) Ags. This functional distinction between TD and TI responses correlates with the presence of two distinct B-cell populations: follicular and MZ B-cells, respectively. To be fully efficient in inducing an $\mathrm{Ab}$ response, the latter B-cells must establish interactions with particular subsets of macrophages, DCs and fibroblast-like cells, and must respond to environmental cytokines in a wellcontrolled spatiotemporal manner. Mouse macrophages and MZ B-cells, firmly attached to sinus lining cells and reticular fibroblasts bordering the MZ, are kept in close proximity to each other and are locally exposed to blood-borne pathogens. Two discrete subsets of macrophages, the Marginal Metallophilic Macrophages (MMM) and the Marginal Zone Macrophages (MZM), populate the mouse $\mathrm{MZ}$ where they perform specialised functions. Both MZM and a subset of MMM express the type I scavenger receptor, MARCO (macrophage receptor with collagenous structure) [29]; however, MMM characteristically express sialic acid-binding Ig-like lectin-1 (Siglec-1, Sialoadhesin, CD169) and MZM characteristically express the C-type lectin, SIGN-R1 (specific intracellular adhesion molecule-3 grabbing non-integrin homolog-related 1, the murine homolog of human DCSIGN - Dendritic cell-specific ICAM grabbing non 
integrin/CD209). MMM are essential for cross-presentation of blood-borne antigens by splenic $\mathrm{CD}^{+} \mathrm{DC}$ and initiation of the cytotoxic T-cell response [30], while MZM preferentially act as phagocytic cells responsible for clearing blood-borne pathogens harbouring TI Ags and apoptotic material entering the spleen [31,32]. Once MZM bind pathogens, they establish the direct cell-cell interactions with MZ B-cells required for an efficient $\mathrm{Ab}$ response $[33,34]$. As shown in various models of deficient mice, B-cells are reciprocally required for normal MZ development and maintenance as well as for the presence and functions of MZM [29]. Even in the transient absence of MZ B-cells following administration of LPS or FTY720 (a drug that blocks emigration from lymphoid organs into blood and lymph), MZM quickly lose SIGN-R1 expression and phagocytic activity [35]. In turn, the binding of pathogens to MZ B-cells and the IgM response to polysaccharides only occur when SIGN-R1-expressing MZM are present to first capture pathogens [36]. Moreover, loss of MZM and MMM (by treatment with clodronate-containing liposomes) leads to MZ B-cell loss and impaired trapping of particulate Ag. After treatment, the recovery of MZ B-cells is delayed until MZM and MMM fully repopulate the MZ [35]. In the absence of $\mathrm{MZ}$ B-cells, CD11c ${ }^{+}$dendritic cells normally concentrate in the MZ bridging channels and are redistributed around the MZ, which likely impairs the adaptive immune response as a consequence [37]. Thus, a constant dialogue between MZ B-cells and MZM, and likely with MMM, is mandatory for protecting intact MZ architecture, as well as for efficient clearance of pathogens and immune responses. MZM and MMM also constitute important sources of type I interferon (IFN) during murine infection by HSV (Herpes Simplex Virus) and LCMV (Lymphocytic Choriomeningitis Virus), which control virus replication and induce anti-viral responses [38,39]. This is consistent with type I IFN promoting functional activation of $\mathrm{DC}$ and crosspriming of $\mathrm{CD} 8^{+} \mathrm{T}$-cells in LCMV-infected mice $[40,41]$.

In contrast to the mouse, the human spleen lacks a marginal sinus, and $\mathrm{MZ}$ surrounds B-cell follicles but not the PALS (Periarteriolar Lymphatic Sheath or T-cell rich area). However, the perifollicular zone is an intermediate area between the MZ and the red pulp (Figure 1). This zone presents strong similarities to the red pulp because of terminal sinuses, blood-filled spaces, sheathed capillaries without endothelial lining, and scattered B- and Tcells. Because terminal vessels directly open into the perifollicular zone, Ags and leukocytes likely exit the circulation in this structure and traffic either to the MZ or to the red pulp [42,43]. A meshwork of fibroblast-like cells expressing Alpha Smooth Muscle actin (ASM) and MadCAM-1 (Mucosal addressing cell adhesion molecule 1) subdivides the MZ into a large inner and a small outer compartment, the latter being in close contact with the perifollicular zone. Along the network of ASM-positive cells, a small ring of B-cells delimits the T-cell zone from the red pulp, whereas a ring of $\mathrm{T}$-cells is frequently present between the inner and outer MZ [44]. The MZM and MMM subsets that respectively populate the outer and inner MZ in mice are lacking in humans. However, human macrophages expressing CD68 (lysosome/macrosialin) and CD169 preferentially form sheaths around capillaries in the perifollicular area, and they can also be present as scattered cells expressing DC-SIGN $[45,46]$. Whether these macrophages may replace MZM in trapping pathogens and interacting with MZ B-cells remains to be established. In humans, $\mathrm{CD} 11 \mathrm{c}^{+} \mathrm{CD} 205^{+} \mathrm{DCs}$ are also intertwined with $\mathrm{MadCAM}^{+}$cells at the inner border of the perifollicular zone, whereas $\mathrm{BDCA}-2^{+}$plasmacytoid DCs are present in the MZ and T-cell zones under steady-state conditions [47-50].

\section{Marginal zone B-cells are essential for MZ organisation and functions}

When mature B-cells are gradually depleted experimentally in mice, or when BcR signalling is impaired from the time of birth, MMM and SIGN-R1 ${ }^{+}$MZM are absent from the MZ, leading to the decreased expression of MadCAM-1 in the marginal sinus and to a lack of response to TI Ags [29,35,51]. MadCAM-1 expression, which is essential for proper trafficking of DC and macrophages in the MZ during immune responses and normal marginal sinus organisation, depends on permanent interactions between membrane lymphotoxin $\beta$ (LT $\beta)$ expressed by lymphoid cells and its receptor expressed by sinus lining endothelial cells $[52,53]$. While MZ B-cells can provide LT $\beta$ signals that induce MadCAM-1 expression during adult life, naïve follicular B-cells and as yet unknown non-lymphoid cells deliver signals requested during mouse and likely human neonatal life [53]. Recent data on subcutaneous infection of mice by VSV (Vesicular Stomatitis Virus) have demonstrated that $\mathrm{CD} 169^{+}$macrophages in the subcapsular sinus of lymph nodes have neuroprotective functions [54]. Similar to the situation in the spleen MZ, B-cell derived LT $\beta$ renders these $\mathrm{CD} 169^{+}$macrophages capable of replicating VSV and of producing type I IFN. Therefore, B-cells exert a critical innate function in antiviral immunity by maintaining the specific location, phenotype and functions of $\mathrm{CD} 169^{+}$macrophages in the spleen MZ as well as in the subcapsular lymph node sinus according to the route of virus entry.

In addition to LFA1 and $\alpha 4 \beta 1$ (VLA- 4 , very late antigen-4) integrins [55], S1P1 and S1P, receptors 1 and 3 of sphingosine-1-phosphate, contribute to the retention of MZ B-cells in the MZ, whereas follicular B-cells expressing higher levels of CXCR5 freely circulate towards the 

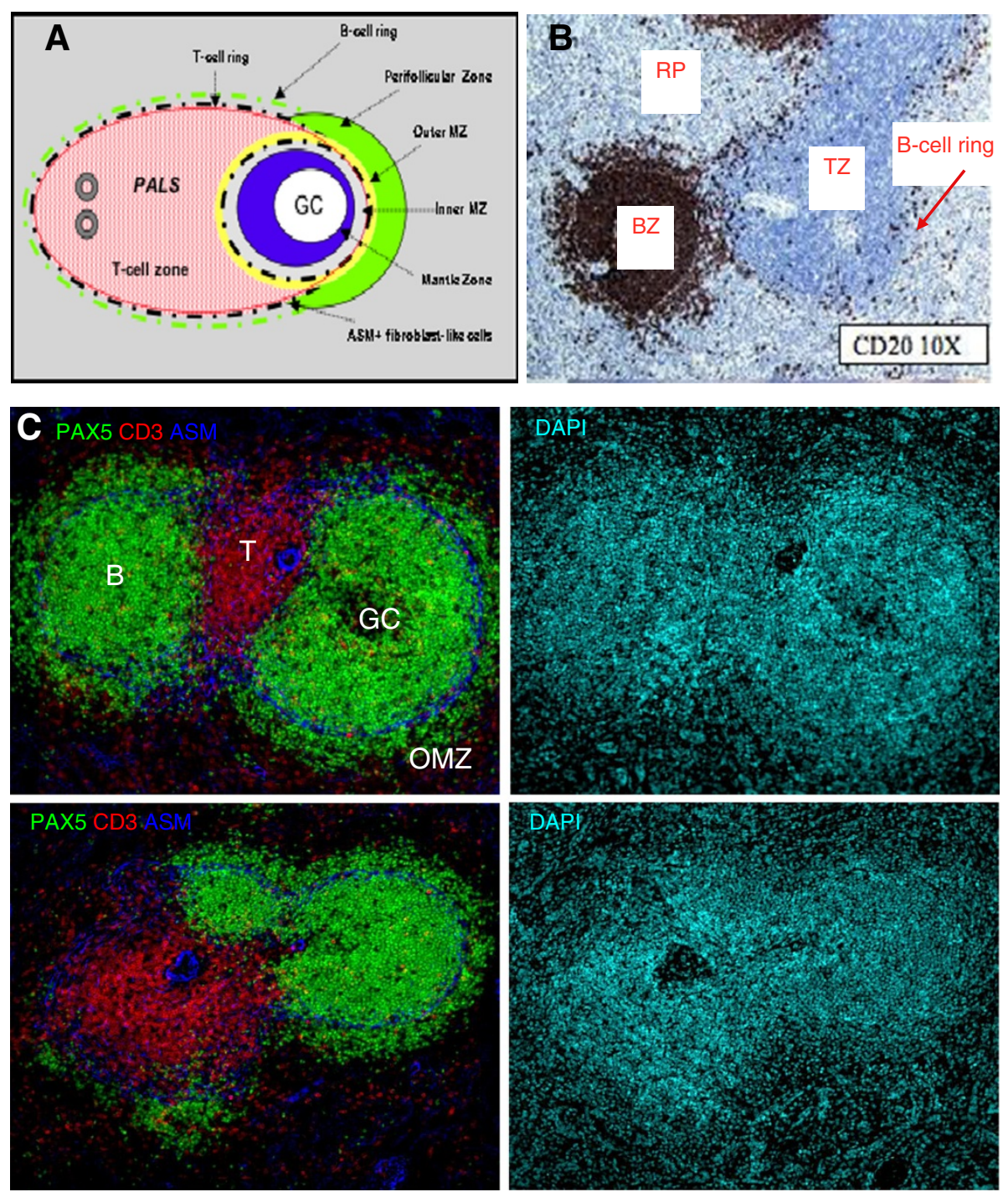

Figure 1 Organisation of the follicular and MZ B-cell compartments in the human spleen. (A) Schematic representation of the various Tand B-cell areas in the human spleen. PALS: periarteriolar lymphatic sheath (T-cell zone). (B) Staining of paraffin-embedded sections of human spleen with CD20 mAb revealed B-cell follicles (BZ) and a ring of B-cells separating the T-cell zone (TZ) from the red pulp (RP) (original magnification x10). (C) Sections of human spleen were simultaneously stained with PAX5, CD3 and ASM (alpha smooth muscle actin) mAbs. The network of fibroblast-like cells stained with the anti-ASM mAb (blue) subdivides the outer (OMZ) from the inner marginal zone around B-cell follicles (PAX5+, green) and separates the T-cell zone (CD3+, red) from the RP (left panels) (original magnification x10). In the upper left panel, a germinal centre $(\mathrm{GC})$ is visible within the B-cell follicle. General tissue organisation is shown by DAPI staining of nuclei (right panels).

white pulp [56]. Thus, the balance between sphingosine1-phosphate and CCL21/CXCL13 plays a determining role in the integrity of the marginal sinus and the retention of MZM and MZ B-cells [57-59]. Impaired CCL21 production correlates with a loss of MZM and reduced pathogen clearance after infection by Leishmania donovani $[57,60]$. These data clearly demonstrate that the proper positioning of MZ B-cells is strongly dependent on the integrity of the sinus-lining cells [52], and that Bcells are crucial for the development (follicular B-cells) and maintenance (MZ B-cells) of a functional spleen
$\mathrm{MZ}$ or its equivalent in the subcapsular sinus of lymph nodes.

MZ B-cells: a particular subset of memory B-cells in humans In mice, orientation towards follicular or MZ B-cell differentiation pathways likely depends on the interplay between BcR and Notch2 signalling. Although absent from the BM, Delta-like 1, a ligand of Notch2, is expressed by splenic red pulp venules and possibly by some stromal cells. No MZ B-cells develop in mice conditionally deficient for Notch2 or Delta-like 1 [61,62]. Follicular B- 
cells develop in a Notch-independent, but a BcR- and BtK-dependent, fashion $[63,64]$. As shown by Loder et al., the progression from immature B-cells into mature B2 B-cells is accompanied by a proliferative burst and is governed by a BcR-mediated selection process [65]. According to the "signal-strength" model proposed by Pillai and co-workers, the strength and duration of the BcR signal play a determining role in the differentiation of either follicular or MZ B-cells (Figure 2). Indeed, when self-antigens trigger $B c R$ poorly, the downstream BtK signalling pathway is insufficient to prevent transcription of Notch2-related genes. BAFF ( $B$ cell activating factor of the TNF family) then allows the survival of these B-cells, which thus differentiate into MZ B-cells. Conversely, when BcR is strongly triggered by "high-affinity" self-antigens, B-cells differentiate in a BtK-dependent manner into follicular B-cells $[61,63,66]$. Reciprocally, only strong $\mathrm{BcR}$ signals leading to potent Btk activation can counteract the Notch2-induced cleavage initiated by Delta-like 1 (Figure 2). Therefore, weak signals delivered by the $\mathrm{BcR}$ appear to be permissive for MZ B-cell development [61,66].

Mouse and human MZ B-cells can be distinguished from follicular naïve B-cells as being $\operatorname{SIgM}^{\text {hi }} \mathrm{CD} 21^{\text {hi }} \operatorname{SIgD}^{\mathrm{lo}}$ and
CD23-. In humans, MZ B-cells are $\mathrm{CD} 27^{+}$memory B-cells that express somatically mutated Ig $\mathrm{V}_{\mathrm{H}}$ genes [67-69]. As compared with naïve B-cells, blood and spleen MZ B-cells harbour shorter length $V_{H}$ CDR3 in adults but also in young infants, indicating that selection can take place in the absence of antigenic responses [70]. By means of $\mathrm{H}-$ CDR3 spectra typing on B-cell subsets present in CD40and AID-deficient infants compared with age-matched healthy infants, Weller et al. have established that MZ Bcells mutate their BcR independently of Ag driven immune responses [69,71,72]. The frequency of $\mathrm{V}_{\mathrm{H}}$ gene mutation in blood MZ B-cells reaches adult values by two to four years of age, and MZ B-cells express a higher clonal diversity than in other memory B-cells in adult individuals $[69,71]$. These authors therefore suggested that MZ B-cells express a "pre-diversified" Ig repertoire specialised in their response to TI Ags [69,72]. BAFF (produced in the MZ) has been proposed to be a key contributor to the diversification of the MZ B-cell repertoire through Activation Induced cytidine Deaminase (AID)-dependent mechanisms [73]. However, only very rare MZ B-cells express AID in human spleen: this suggests that alternative processes exist (although they have not yet been identified) [74]. BAFF is a key survival factor for MZ B-cells that also favours the
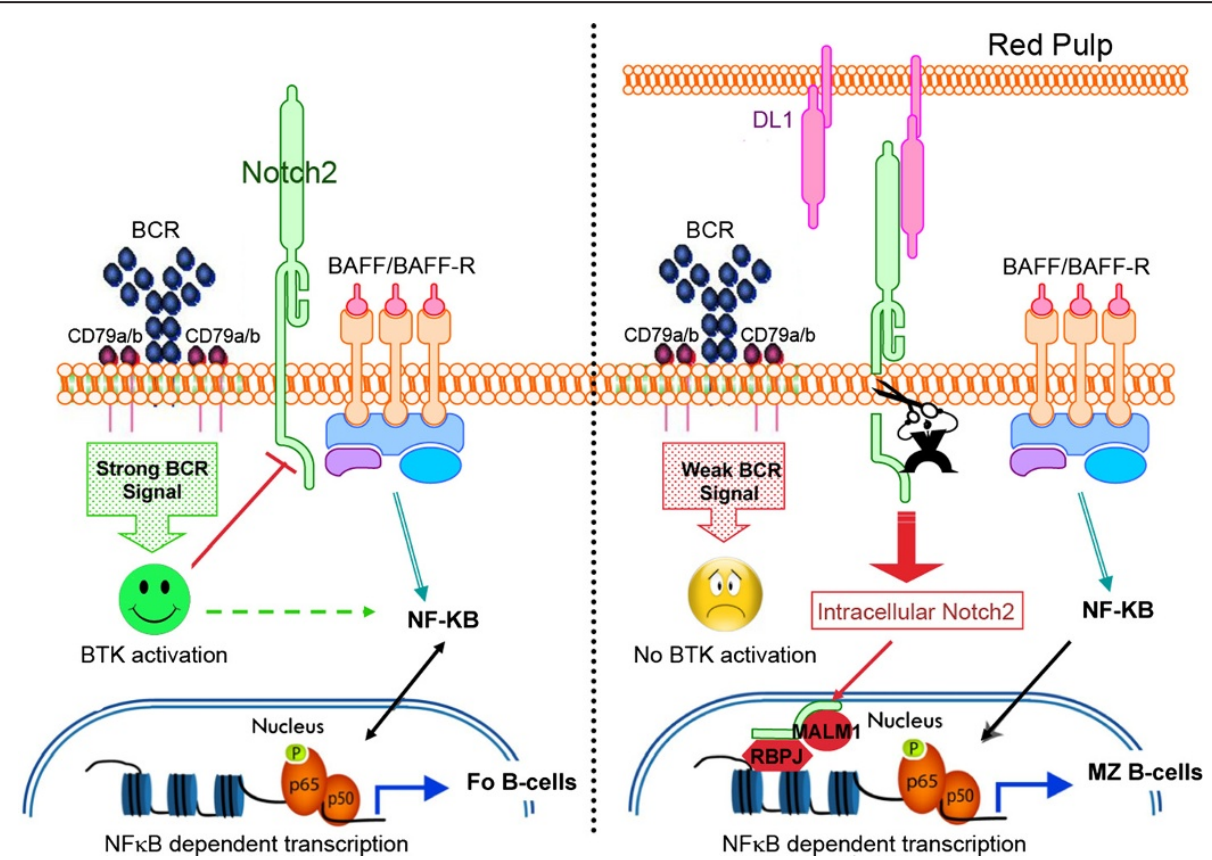

Figure 2 Becoming a follicular or a MZ B-cell?. Left panel: Strong signalling through BcR activates Bruton's tyrosine kinase (BTK), which in turn activates the canonical nuclear factor-kB (NF-kB) signalling pathway and prevents the cleavage of Notch2. BAFF-BAFF-R interactions deliver survival signals through NF-KB activation. Right panel: Notch2 can interact with its ligand, Delta-Like 1 (DL1), specifically expressed by the endothelial cells of red pulp venules in mice. This interaction initiates the cleavage of Notch2, which is not inhibited by weak BcR signalling. The intracellular domain of Notch2 enters into the nucleus where it interacts with Mastermind-like 1 (MAML1) and RBP-J transcription factors. This transcriptional complex induces the commitment of B-cells towards MZ B-cells. BAFF-BAFF-R interactions deliver survival signals through canonical NF-KB activation. 
survival of self-reactive B-cells when it is overproduced locally in response to viral infection or chronic inflammation [75]. Deregulated BAFF expression is a feature of numerous autoimmune diseases such as rheumatoid arthritis, lupus erythematosis and Sjögren's disease, where functional BAFF would promote the emergence/survival of selfreactive pathogenic B-cells [75]. In patients with Sjögren's disease, where BAFF is locally produced by salivary epithelial cells and infiltrating $\mathrm{CD}^{+}$T-cells [76], BAFF levels correlate with autoantibody levels in serum [77]. Mice transgenic for BAFF can develop Sjögren-like syndromes characterised by expansion of pathogenic B-cells with an MZ-like phenotype. Depletion of MZ B-cells totally prevents this syndrome but does not prevent nephritis, which is also observed in these mice [78]. Consistent with a possible association between viral infection and Sjögren syndrome, Ittah et al. have shown that triggering of TLR3 by synthetic agonists or dsRNA does induce exaggerated BAFF production by salivary gland epithelial cells [79]. More recently, these authors have suggested a comprehensive role of viral infection in BAFF production by epithelial cells and monocytes through Type I IFN-dependent and independent mechanisms [80]. In macaques experimentally infected with a pathogenic strain of Simian Immunodeficiency Virus (SIV), we have recently described elevated plasma levels of BAFF, but not APRIL (A ProliferationInducing Ligand), during the acute phase of infection [81]. The proportions of MZ B-cells strongly decreased in blood, lymph nodes and spleen because of increased apoptosis and their differentiation into polyclonal plasma cells located in the MZ and lymph node sinus, where BAFF over-expression was concurrently observed $[81,82]$. Therefore, cognate interactions with the virus and virus-induced cytokines likely synergize to promote MZ B-cell differentiation into multi-reactive plasma cells during acute SIV infection. In contrast, the over-expression of BAFF within GCs would impair the selection process of SIV-specific plasma cell precursors, contributing to the delayed SIVspecific antibody detection $[81,82]$. We are currently addressing this question in SIV-infected macaques treated or not with BR3-Fc, a BAFF antagonist currently used for treating patients with rheumatoid arthritis or lupus erythematosis.

\section{Marginal zone B-cells: a dual role in T-independent and T-dependent responses}

Interactions of MZ B-cells with pathogens (particularly bacteria) elicit their rapid activation and secretion of IgM, which constitutes the first line of defence against these pathogens. The IgM molecules produced are of low affinity but exhibit a broad specificity, meaning that they can bind a variety of Ags with overlapping or close epitopes, favouring the neutralisation and clearance of a larger variety of (bacterial and viral) pathogens. In addition to their role in the innate response, MZ B-cells are endowed with the ability to import high molecular weight Ags $(>200 \mathrm{kDa})$ and viral particles into follicles, a mechanism that can accelerate the adaptive response against pathogens and widen the repertoire of Ags present in GC [56]. In most cases, stimulation of these MZ B-cells occurs independently of the BcR, through triggering of TLRs or other PRRs. Through their capacity to shuttle between MZ and B-cell follicles, MZ B-cells rapidly transport IgM-containing immune complexes delivering pathogen-derived Ags and/or viruses into B-cell follicles where they can rapidly stimulate the onset of primary TD responses [56,83]. Under physiological conditions, MZ B-cells re-enter the MZ once they have delivered Ags to follicular DC within GCs $[56,83]$. During chronic infection or inflammation, overproduction of type I IFN plays a major role in the longlasting sequestration of B-cells within the follicles by modifying their responsiveness to S1P $[84,85]$. This Bcell sequestration would favour Ag delivery to follicular DC and interactions between rare T- and B-cells with identical Ag specificity at the border of follicles [56]. Conversely, long-term exposure to type I IFN might have immunosuppressive effects on the B-cell response by interrupting the shuttling of MZ B-cells into the white pulp. Besides type I IFN, we have shown that BAFF might prolong the follicular sequestration of MZ B-cells through its ability to preferentially enhance the chemotaxis of $\mathrm{CD} 27^{+}$memory B-cells to CXCL13, [86]. This might particularly occur during HIV/SIV infection [82] or chronic inflammatory diseases where type I IFN and BAFF are concurrently over-produced (Figure 3).

In summary, MZ B-cells, which primarily mount TI responses with so-called "natural" IgM Abs of low affinity and large specificity to a variety of pathogens, can also migrate to follicles where they contribute, via harboured $\mathrm{IgM} /$ pathogen complexes, to the initiation of another type of $\mathrm{Ab}$ response (that of high affinity/ restricted specificity) requiring cognate interactions with helper T-cells.

\section{Evidence for a protective role of marginal zone B-cells in systemic bacterial infection}

MZ and microbial responses in infants Consistent with data in mice showing that the marginal sinus undergoes organisation during the three first weeks of life [53], ASM expression in infants is rapidly observed around B-cell aggregates after birth. This "rudimentary" MZ organisation attains the adult morphology only after 4 months [87]. Based on the expression of CD21 or $\mathrm{CD} 1 \mathrm{c}$, conflicting data have been reported regarding the colonisation of MZ by MZ B-cells before 2 years of age. Indeed, the group of $\mathrm{W}$. Timens reported that naïve but 


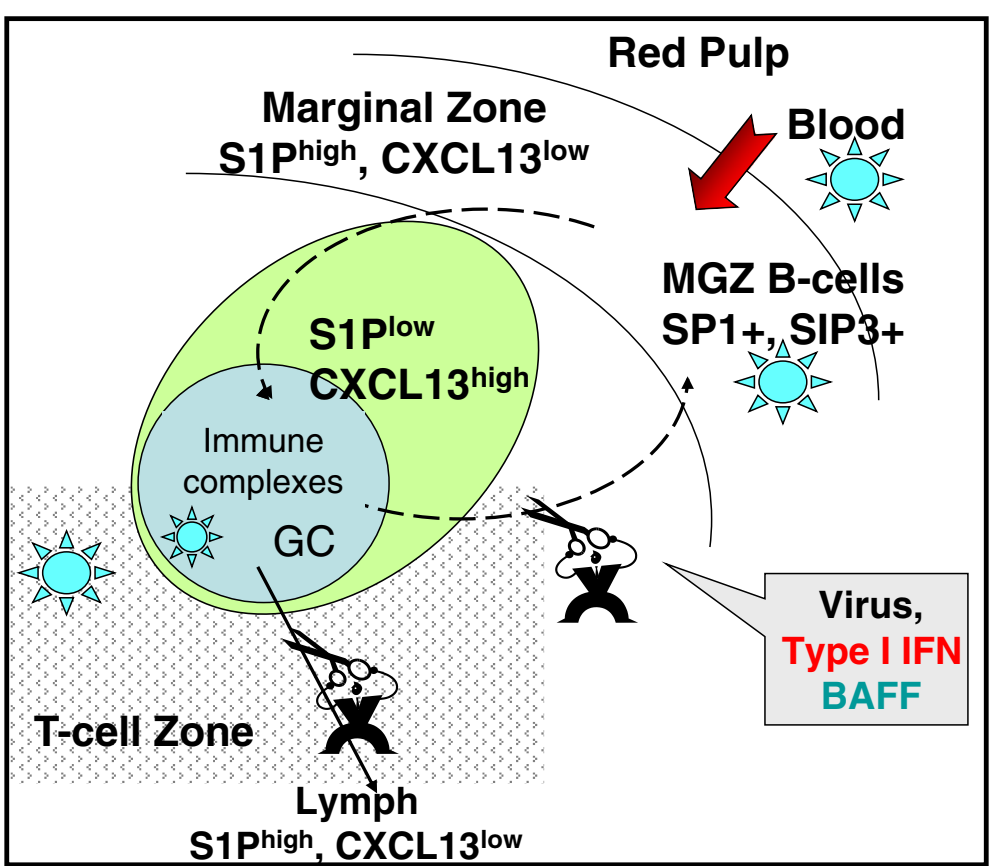

Figure $3 \mathrm{MZ}$ B-cells shuttle between the MZ and follicles and transport Ag and pathogens to follicular DC. In steady-state conditions, strong expression of LFA1 and a $4 \beta 1$ integrins and receptors 1 and 3 of Sphingosine 1-Phosphate (S1P) on MZ B-cells, together with high levels of S1P in blood, contributes to the retention of MZ B-cells within the MZ. Type I IFN produced in response to blood-borne pathogens inactivates S1P1 and 3, allowing MZ B-cells to migrate in response to CXCL13, which is highly expressed in follicles. During this relocation, MZ B-cells can transport immune complexes bound to non-BCR receptors and deliver them to follicular DC (FDC). Once on FDC, these import Ags participate in the adaptive Ab response [56,83]. Rapid ligand-induced desensitisation of CXCR5 authorizes MZ B-cells to return to the MZ. Overproduction of BAFF, which preferentially increases the chemotaxis of CD27+ MZ and memory B-cells to CXCL13 might also impair this shuttling and lead to prolonged sequestration of MZ B-cells within follicles [86]. Such a mechanism would be at work during acute infection by SIV, where it might favour sequestration of activated B-cells within follicles [82].

not $\mathrm{CD} 21^{+} \mathrm{CD} 27^{+}$B-cells were present in the $\mathrm{MZ}$ prior to the age of 2 years, and they additionally showed that $\mathrm{MZ}$ B-cells increased in numbers between the ages of 2 and 5 years, where they reached adult levels [87]. Moreover, even if switched CD27 ${ }^{+}$memory B-cells can be generated in vaccinated infants at 4 to 6 months after birth, they are unable to home into $\mathrm{MZ}$ as they do in adults. Responses to polysaccharides occur concurrently with the expression of CD21 in the MZ [88]. Therefore, cellular components other than MZ B-cells are probably absent or not fully functional before the age of two, which limits their homing/sequestration in MZ. In contrast, Weill et al. observed CD1c expression in the spleen MZ in 8-month-old infants; they also consistently detected B-cells with a MZ B-cell phenotype in spleens of infants below 2 years of age [72]. However CD1c was previously demonstrated to be expressed by about $50 \%$ of spleen and blood B-cells, and to be consistently present on mantle zone, likely naïve, B-cells [89]. While definitive conclusions regarding the kinetics of $\mathrm{MZ}$ colonisation by $\mathrm{MZ}$ B-cells require additional studies, it is clear that MZ is not fully functional below 2 to 4 years of age, an observation consistent with high susceptibility of children less than 2-3 years of age to infections by encapsulated bacteria and defects in long-lasting protection towards the polysaccharide pneumococcal vaccine $[90,91]$. Bearing in mind the importance of the dialogue between MZ B-cells and either macrophages or DC subsets in mice, one can speculate that the homing of these populations within the human MZ plays a similar crucial role in $\mathrm{MZ}$ function. However, little is known about the kinetics and the precise nature of DC and macrophages that populate the $\mathrm{MZ}$ during the first months of life and their capacity to express integrins, BAFF/APRIL, and chemokines known to regulate the homing and survival of MZ B-cells in situ. Neutrophils may play a previously underappreciated role as potent producers of BAFF/ APRIL and IL21 in the perifollicular zone of human spleen that supports Ig class switching, somatic mutation and Ab production by MZ B-cells [92].

\section{Lessons from aging, splenectomy and diseases.}

Aging in humans and mice is associated with a decline in protective immunity and increased susceptibility to infection by encapsulated bacteria, increased autoimmune manifestation, and reduced response to 
vaccination. Decreased responses to TI antigens in old mice have been associated with reduced proportions of MZMs and MZ B-cells, collapse of MZ architecture, and disturbed MadCAM-1 expression by sinus lining cells [52]. In humans, invasive pneumococcal disease increases with age, over 65 in particular [93]. The inefficient Ab response in aged individuals is thus assumed to be associated with altered functions of the spleen MZ $[88,94]$. Individuals with splenic dysfunction or having undergone splenectomy are highly susceptible to infection with Streptococcus pneumonia, Heamophilus influenza, Neisseria meningitis and other encapsulated bacteria, which correlates with a defect in circulating MZ B-cells and a lack of $\mathrm{Ab}$ response against these pathogens [95]. In patients with common variable immunodeficiency, those presenting with recurrent infection of the respiratory tract and chronic lung disease have an extremely low frequency of IgM memory B-cells and do not produce antipolysaccharide IgM $[96,97]$. Splenic dysfunction may also occur in patients with sickle cell anaemia [98], inflammatory bowel disease [99] or celiac disease [100], where both impaired IgM production by MZ B-cells and reduced phagocytosis of opsonised particles prevent the clearance of encapsulated bacteria.

Taken together, these observations indicate that the spleen exerts a dedicated function that is not completely substituted by other secondary lymphoid organs. It is noteworthy, however, that a normal blood MZ B-cell compartment is present in young children with congenital asplenia, suggesting that MZ B-cell precursors can colonize alternative sites for their development [69]. Similarly, cells with the morphology and phenotypes of MZ B-cells have been observed in the subcapsular sinus of lymph nodes, under the dome epithelium of Peyer's patches in the gut, and in the crypt epithelium of tonsils [101-104]. Whether these cells have a similar role to spleen MZ in the defence against encapsulated bacteria remains to be established. Recent data showing the unique ability of B-cells to maintain the location and functions of subcapsular $\mathrm{CD} 169^{+}$macrophages during innate antiviral immunity strongly support this hypothesis [54].

\section{Human B-cells express Toll-like receptors that define anatomical and functional subsets}

TLRs are commonly divided into two subgroups depending on their cellular localisation and respective PAMP ligands. The first group is composed of TLR1, TLR2, TLR4, TLR5, TLR6 and TLRs 10-13, which are expressed on cell surfaces and recognize mainly microbial surface components. The second group is composed of TLR3, TLR7, TLR8 and TLR9, which are preferentially sequestered in the endoplasmic reticulum in resting cells and rapidly traffic to endolysosomes after stimulation by microbial nucleic acids [105]. In contrast to mouse Bcells, human B-cells express neither TLR4 nor CD14, the two canonical ligands for $\mathrm{Gram}^{-}$bacteria LPS, and are therefore unresponsive to LPS. In healthy donors, circulating naïve and memory B-cells express distinct amounts of TLR1, 2, 6, 7, 9 and 10 and are negative for TLR $3-5$ and $8[3,10,106]$. However, elegant studies by Cerutti's group have clearly shown that functional TLR3 is expressed by human tonsillar B-cells, with higher expression in GCs and sub-epithelial regions, but is absent from memory B-cells. In the presence of dsRNA, these mucosal B-cells up-regulate AID expression and initiate class switch recombination and IgG/IgA production in the presence of IL-10 and BAFF [107]. Restricted to a discrete population of $\mathrm{CD} 27^{-}$blood B-cells with intermediate levels of CD19, TLR2 is preferentially expressed by naïve and GC B-cells present in mucosa or exposed to inflammatory stimuli. MZ B-cells, as well as mucosal follicular naïve B-cells, strongly express TLR2/TLR1 and TLR2/TLR6 complexes and thus recognize a panoply of unrelated molecules, including peptidoglycans, diacylated and triacylated lipopeptides, and porins from a broad spectrum of microbes [108]. BcR cross-linking with anti-Ig antibodies or protein A from Staphylococcus aureus sensitizes B-cells to TLR2-active diacylated and triacylated lipopeptides, which promote their proliferation and differentiation into IgM-producing cells $[106,109]$. Accordingly, TLR2 ligands are effective adjuvants in humans and are currently used in the Haemophilus influenzae type B vaccine. In vitro, TLR2 ligands also induce CCR9, CCR10 and J chain expression on human B-cells and enhance IgA production [23], suggesting that TLR2 activation might favour intestinal homing. It is not clear yet whether this effect ameliorates the mucosal response or induces tolerance.

In humans, TLR9 expression is restricted to B-cells [10], plasmacytoid DCs (pDCs) [7] and platelets [110], whereas TLR7 is more widely distributed among the various populations of APCs. TLR7 and TLR9 are consistently present in all B-cell subsets, with the majority of TLR molecules sequestered in the endoplasmic reticulum. Activation of TLR9 requires its cleavage by endolysosomal proteases [111], and TLR9 is detectable within small intracellular vesicles of primary B-cells [112]. Memory B-cells contain higher amounts of TLR9 than naive B-cells [113], and we found that a fraction of TLR9 molecules can traffic to the plasma membrane [10]. BcR- and CD40-mediated stimulation transiently increases TLR9 expression, which enhances responsiveness to its agonist, CpG DNA, proliferation, chemokine production and APC function $[7,114]$. Besides BcR and CD40 ligation, Type I IFN produced by pDCs increases TLR7 and MyD88 expression in naïve peripheral human B-cells [115], and therefore their responsiveness to TLR7 
agonists. Mouse TLR10 is not functional because of a retroviral insertion, and TLR11-13 have been lost from the human genome [105]. While TLR10 expression is also restricted to B-cells and pDCs, its role in B-cell physiology remains to be clarified in the absence of recognition of any specific ligand. Human TLR10 is strongly related to TLR1 and 6 and associates with TLR2. While TLR10/TLR2 complexes recruit MyD88 after TLR2 ligand-induced stimulation, they fail to activate typical TLR-induced signalling, including NF-кB [105]. However, it seems likely that TLR10 is functional because TLR10 gene variants have been associated with susceptibility to asthma [105].

Thus, TLR expression is constitutive in human B-cells, assigning these cells a functional role in sensing infectious danger and participating in innate immunity; this function is well understood in mucosal surfaces but less so in other compartments. There are indications that B-cells display various arrays of TLR molecules that seem to characterize subsets. A question that is beginning to be addressed is whether TLR binding of pathogen-derived material tethers pathogen-derived Ags when the $\mathrm{BcR}$ is of low affinity (IgM). This may be the case for MZ B-cells, although this has not yet been ascertained because of the puzzling observation that $\mathrm{MZ}$ B-cells are $\mathrm{CD} 21^{\mathrm{hi}}$. The consequences of dual B-cell stimulation through a PRR (e.g., a TLR) and $\mathrm{BcR}$ deserve further exploration, particularly on $\mathrm{Ab}$ responses initiated by a TI Ag.

\section{Cross-talk between CD1 ${ }^{+}$MZ-B-cells and NKT cells}

Recent studies have demonstrated that in addition to the BcR-mediated uptake described for specific lipid Ags $[116,117]$, B-cells can use an apolipoprotein-mediated pathway of lipid Ag uptake for presentation to innatelike NKT cells. Indeed, invariant NKT-cells (iNKT), a subset of NKT-cells, recognize exogenous and self-lipids as well as glycolipid Ags (LPS-free) presented by CD1d, a non-classical class I molecule. Through their characteristically high expression of CD1d, MZ B-cells may establish cognate interactions with iNKT in the MZ [118] and elicit a stronger lipid-driven NKT-cell stimulation than follicular B-cells [119]. The uptake of lipid Ags requires the expression of the low-density lipoprotein receptor (LDL-R) by B-cells, a BcR-independent uptake pathway [120] that probably favours the production of "polyreactive" (innate), and even self-reactive, Abs. While the BcR-mediated route facilitates the uptake of particulate lipid Ags and their transport to CD1dcontaining endocytic vesicles, this pathway likely favours a more lipid-specific Ab response [118] (Figure 4). Although direct stimulation of TLR2, 7 and 9 by their ligands elicits IL-6, IL-10 and IFN $\beta$ (TLR9 only) production by MZ B-cells in mice, it does not result in cognate interactions with iNKT [121]. These results show that

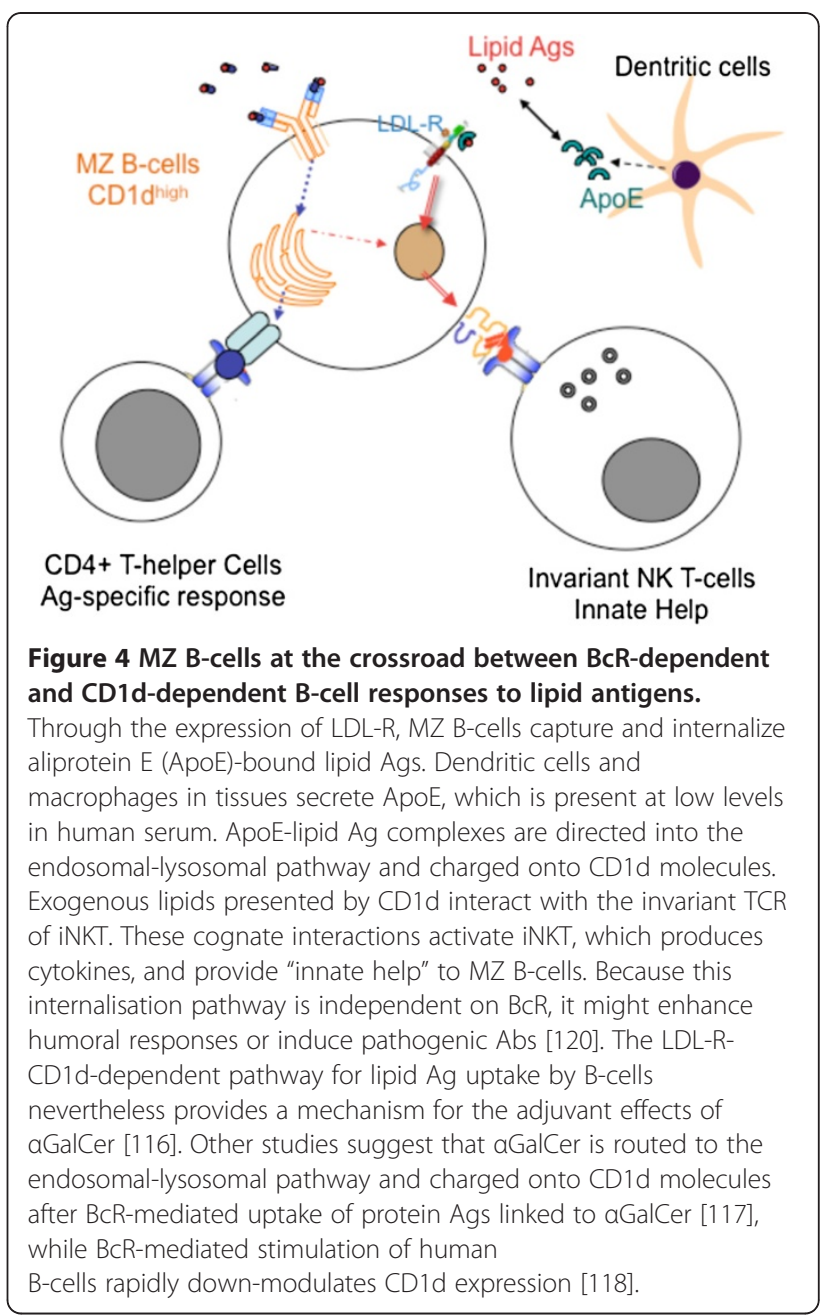

MZ B-cells may differentially contribute to humoral immunity according to their activation route and the nature of the Ag. Moreover, part of the innate Ab response depends on rapid but transient cognate interactions between MZ B-cells and NKT-cells. Recent studies have shown that impaired CD1d recycling in patients with systemic lupus erythematous, as compared with healthy individuals, causes defective B-cell mediated iNKT stimulation. This work highlights the physiological importance of B-cells in lipid presentation to iNKT during the innate immune response [122].

The case of regulatory B-cells in mice and their potential equivalents in humans

B-cells are generally considered positive regulators of the immune response (their major regulator in Ig secretion function being Ig binding through the FcyRIIb itself). However, several regulatory B-cell subsets can negatively regulate these immune responses [123-125]. A general feature of these regulatory B-cells is to preferentially produce IL-10 upon appropriate stimulation [126-128], 
but this is not a unique feature. In particular, B10, a potent regulatory $\mathrm{B}$-cell subset within the rare $\mathrm{CD} 1 \mathrm{~d}^{\mathrm{hi}} \mathrm{CD} 5^{+}$ B-cell subset of the spleen, has been shown to regulate acute inflammation and autoimmunity through the production of IL-10 [126,127]. Based on the expression of TIM-1 (T-cell Ig domain and Mucin domain protein 1), mouse B10 cells can be further distinguished from B-1a and MZ B-cells [129]. BAFF was recently shown to induce or expand B10 cells in mice [130].

Data obtained following B-cell depletion by treatment with Rituximab (a chimeric CD20 mAb), Ofatumumab or Ocrelizumab (two fully humanised anti-CD20 mAbs) in patients with autoimmune diseases or having undergone $\mathrm{BM}$ transplantation strongly support the existence of regulatory B-cells in humans [131]. However, it is not clear whether they constitute a distinct lineage or a subset, and have sufficient plasticity to change their effector functions into regulatory ones. IL-10-producing regulatory B-cells have been described in healthy individuals, as well as in patients with autoimmune disease $[132,133]$. In contrast to mice where B10 cells are naïve B-cells, human IL-10-producing B-cells have been characterised either as memory $\left(\mathrm{CD} 27^{+}\right)$or immature transitional $\left(\mathrm{CD} 38^{\text {hi }} \mathrm{CD} 24^{+}\right)$B-cells. Only a population of human $\mathrm{CD} 19^{+} \mathrm{CD} 24^{\text {hi }} \mathrm{CD} 38^{\text {hi }}$ B-cells was shown to exert regulatory functions on $\mathrm{CD} 4^{+}$T-cells [134]. Recent data from Iwata et al. partially reconcile these data by showing that both human B10 cells and their precursors belong to a CD24 $4^{\text {hi }} \mathrm{CD} 27^{+}$B-cell population [133]. Thus, human B10 cells, similar to MZ B-cells, differ from mouse B10 cells by expressing a memory phenotype. The distinct organisation of MZ in mouse and human probably facilitates different interactions between MZM, DC and B-cell subsets [135]. In this context, it will be important to better identify BAFF-producing cells in human MZ because BAFF is likely involved in the differentiation or survival of human B10. Indeed, treatment of patients with multiple sclerosis (MS) with Atacicept (TACI-Ig), an antagonist of BAFF and APRIL, led to an unexpected increase in inflammatory activity and condemned the Atacicept trials in MS [136]. These data strongly support the notion that human B10 cells are also dependent on BAFF. While the various human B10 subsets produce IL-10 only after appropriate stimulation, a distinct population of $\mathrm{CD} 20^{+} \mathrm{CD} 27^{+} \mathrm{CD} 43^{+} \mathrm{CD} 11 \mathrm{~b}^{+} \mathrm{B} 1$ cells produce it spontaneously [137]. This population also down regulates the $\mathrm{T}$-cell response. The respective role of these various IL-10-producing cells deserves to be extensively examined.

\section{CD21 ${ }^{\text {lo/- }}$ B-cell populations: from aging to HIV infection}

As previously discussed, ageing is accompanied by compromised immune responses and an increased propensity for autoimmunity. Besides reduced numbers of both hematopoietic stem cells entering into the lymphoid lineages and of MZ B-cells, accumulation of an exhausted B-cell population has recently been reported in aged mice [138]. With no surface CD21, CD23 and CD43, these $\mathrm{CD}_{1}{ }^{\text {hi }}$ SIgM $^{+}$BAFF-R ${ }^{+}$B-cells differ from MZ, B1 and follicular B-cells. These B-cells further exhibit impaired functional responses to $\mathrm{CD} 40$ and $\mathrm{BcR}$ ligands, and to BAFF, and produce IgM, IL-4 and IL-10 only in response to TLR9 and TLR7 stimulation. Moreover, these B-cells are prone to induce IL-17 production by activated T-cells at the expense of $\mathrm{T}$ follicular helper cell generation, thus thwarting the interactions necessary for affinity maturation and memory cell formation [139].

In aged female mice and in mice presenting with autoimmune pathologies, an accumulation of $\mathrm{CD} 21^{\mathrm{lo} /-} \mathrm{CD} 11 \mathrm{c}^{+}$ B-cells has also been described [140]. These $\mathrm{CD} 11 \mathrm{c}^{+} \mathrm{CD} 21^{-}$ B-cells, which are also $\mathrm{CD}^{+}$and $\mathrm{CD} 138^{+}$, express high levels of CD95, CD80 and CD86. Unresponsive to BcR triggering, these B-cells secrete high levels of antichromatin IgG following TLR7 stimulation. Intact TLR7 signalling is required for the development of this population in mice. In humans, this population of $\mathrm{CD} 21^{-} \mathrm{CD} 11 \mathrm{c}^{+}$ B-cells is CD $5{ }^{\text {hi }} C D 80^{\text {hi }} C D 86^{\text {hi }} C D 20^{\text {hi }} C D 23^{-}$, but CD $27^{\text {hi }}$, and does not express any surface immunoglobulin; it therefore resembles plasmablast precursors [140]. A high frequency of circulating $\mathrm{CD} 21^{\text {lo }} \mathrm{B}$-cells is associated with a propensity to autoimmunity, and the $\mathrm{CD} 21^{\mathrm{lo}} \mathrm{CD} 11 \mathrm{c}^{+}$ population is found more frequently in the blood of elderly female patients with autoimmune disorders than in healthy age-matched individuals $[11,141]$. First described by Ehrhardt et al. as a unique population of memory B-cells expressing mutated BcR but not CD27, the FcRL4 ${ }^{+}$ ( $F$ c receptor-like protein 4 ) population normally resides in epithelial tissue-associated niches [142-145], but is expanded in the blood of patients with common variable immunodeficiency [146]. Because FcRL4 disrupts immune synapse formation and blocks antigen-induced BcR signalling, FcRL4 ${ }^{+}$B-cells are unresponsive to BcR ligands, but still responsive to CD40L, TLR9 agonists, IL 2 and IL 10 [147]. In viremic HIV-infected patients and patients chronically exposed to plasmodium falciparum, this population of FCRL4 $4^{+} \mathrm{CD} 27^{-}$memory B-cells was found in the blood, where it progressively replaces conventional memory B-cells. In these HIV+ patients, FcRL4 ${ }^{+}$B-cells showed reduced proliferation and differentiation into plasma cells in response to BcR ligands, and also to cytokines and CD40L [148]. In light of this pathogen-induced loss of functions, Moir et al. called these cells "exhausted" memory B-cells. The role of FcRL4 in exhaustion is obvious: downregulation of FcRL4 expression by RNA interference in $\mathrm{CD}_{2} 7^{-}$memory B-cells in HIV-infected patients partially restores their capacity to respond to BcR stimulation and to produce HIV-specific antibodies [149]. At least in HIV-infected patients, these 
Table 1 Summary of main phenotypic and functional characteristics of B-cell subsets

\begin{tabular}{|c|}
\hline Phenotypic marker \\
\hline Marginal Zone B-cells \\
\hline $\operatorname{SlgM}^{\text {hi }} \operatorname{Slg}^{10} C D 27+C D 21^{\text {hi }}$ \\
\hline CD23- \\
\hline $\mathrm{CXCR} 5+\mathrm{S} 1 \mathrm{P} 1^{\text {hi }} \mathrm{S} 1 \mathrm{P} 3^{\mathrm{hi}}$ \\
\hline TLR 2> 1, 6; TLR10 \\
\hline TLR9 $>7$ \\
\hline CD1chi \\
\hline LDL-R+ \\
\hline CD1d ${ }^{\text {hi }}$ \\
\hline BAFF-R++, TACl+ \\
\hline Follicular Naive B-cells \\
\hline SlgM+SlgD ${ }^{\text {hi }} C D 27-C D 21+C D 23^{h}$ \\
\hline CXCR5++ S1P1+ S1P3- \\
\hline TLR $2>1,6$, TLR10 \\
\hline TLR9>7 \\
\hline $\mathrm{CD} 1 \mathrm{c}+, \mathrm{CD} 1 \mathrm{~d}^{\mathrm{hi}}$ \\
\hline BAFF- $\mathrm{R}++, \mathrm{TACl}+$ \\
\hline
\end{tabular}

\section{Conventional Memory B-cells}

SlgD-, SlgG/A>SlgM, CD27+

$\mathrm{CD} 21^{\text {hi }} \mathrm{CD} 23-$

TLR9++, TLR7+

BAFF-R+TACl+

Regulatory B-cells

CD1d ${ }^{\text {hi }}$ CD5+ TIM-1+

CD27+

$\mathrm{CD} 19+\mathrm{CD} 24^{\text {hi }} \mathrm{CD} 38^{\text {hi }}$

\section{CD2 $1^{\text {lo/- }}$ B-cells}

CD19+ SlgM+ BAFF-R+ CD21-

CD23-CD43-

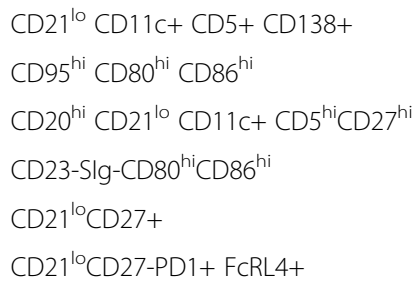

Functions and other characteristics

References

Mutated BCR in humans on $>80 \% \mathrm{MZ}$ B-cells

$67-69,72$

TI-Ab response. Produced Low affinity IgM

CD21 modulates BCR signalling

141

Preferential sequestration in $M Z$, shutling into follicles upon stimulation

$55,56,58,59$

BCR-independent transport of high MW Ags and virus particles into GC

56,83

Present in periphery (blood, Lymph node, spleen) in humans

69

Surface TLRs associated into functional TLR2/1 or TLR2/6 complexes

108,109

Endosomal TLR detecting unmethylated CpG DNA and ssRNA

Expression \ upon CD40L stimulation but $\nearrow$ after BCR triggering

115

Binds and internalizes lipid Ags associated with Apo-E

117

Presents lipid Ags to iNKT

$116,119-122$

118

$119-122$

Cognate interactions with iNKT, which in turn produce IL17 and IL22

75

Role of BAFF in the transient relocalisation of $\mathrm{MZ}$ B-cells into follicles

Unmutated BcR.

Preferential homing to follicles

Surface TLRs associated into functional TLR2/1 or TLR2/6 complexes

108,109

Endosomal TLR detecting unmethylated CpG DNA and ssRNA,

Functional role?

Naive B-cell survival

High affinity hypermutated $B C R$

Role of CD21 in memory B-cell survival

141

$\nearrow$ expression of TLR 7, 9 in memory B-cells compared to naive B-cells

7,113

BAFF preferentially enhances memory B-cell chemotaxis to CXCL13

86

B10:IL10-producing B-cells in mice. Located in/near MZ 123,124

Expanded by BAFF in mice $\quad 130$

IL10-producing memory B-cells in humans

$127,132-134$

IL10-producing transitional B-cells in humans. Regulatory functions on CD4+ T-cells

134

No response to $\mathrm{BCR}, \mathrm{CD} 40$ or BAFF-R stimulation

134

Production of IgM, IL10 and IL4 in response to TLR9, 7 stimulation

Induce IL17 production by activated T-cells

115

Present in aged and autoimmune mice. Pre-plasmablasts?

157

No response to $B C R$ stimulation but produced IgG after TLR7 triggering

Present in blood of elderly female autoimmune patients

Pre-plasmablasts?

Activated B-cells or pre-plasmablasts present in HIV-infected patients

$148-150$

Exhausted tissue-like memory B-cells present in HIV-infected patients 
exhausted memory B-cells express high levels of PD-1 (Programmed Death 1) [148]. During pathogenic SIV infection in macaques, PD-1 drives the rapid and sustained loss of activated memory B-cells $\left(\mathrm{CD} 21^{\mathrm{lo}} \mathrm{CD} 27^{+}\right)$ in the so-called "rapid progressors". This depletion, which constitutes an early predictor of disease progression, can be reversed by blockade of PD-1. In vivo blockade of PD1 in SIV-infected macaques have enhanced polyclonal and virus-specific Ab responses [150]. Whether similar mechanisms/pathways are responsible for CD21 downregulation in HIV-infected patients, patients with autoimmune diseases and aged individuals remains to be firmly established.

\section{Concluding remarks}

In conclusion, B lymphocytes display hallmarks of three distinct functional categories of immune cells (Table 1): i) they bear a unique B-cell receptor for antigen on their membranes, which characterizes conventional B-cells and adaptive immunity; ii) they express CD40 on their surfaces, a property which is shared by most APC (though this is not a unique feature); iii) they express PAMP-ligands i.e. PRRs, which is considered a landmark of innate immune cells. Indeed, human B-cell subsets express distinct PRRs, including FcRs, complement receptors and TLRs. B-cells, despite being from a unique origin, have diversified into distinct subsets, the survival and functions of which are associated with their microanatomical locations. Accordingly, one can distinguish four main orientations. The first orientation comprises conventional, or follicular, B-cells that populate B-cell follicles in secondary lymphoid organs and mucosa, and correspond to the B2 lymphocytes in the mouse system. They principally use their capacity to bind amino acidbased Ags (although independent of APC and HLA in the conformational presentation) through the $\mathrm{BcR}$ and are specialised in the response to TD Ag. Qualified as naïve follicular B-cells before they encounter $\mathrm{Ag}$, they evolve into activated B-cells that populate GCs and into memory or long-lived plasma cells that colonize specific areas around follicles and bone marrow, respectively. The second orientation concerns MZ non-conventional B-cells and B1-like B-cells, that can bind either peptide Ags through their BcR and/or non-peptide Ags such as lipids and polyosides or nucleic acids via a plethora of surface receptors. This subset is specialised for TI-Ab responses and preferentially home in spleen MZ. In contrast to follicular B-cells, which are highly recirculating cells, MZ B-cells have a restricted trafficking pattern. The third orientation is forwards regulatory B-cells (Breg), most of which produce high amounts of IL-10 upon appropriate stimulation. They have been identified both in mouse and humans, and parallel regulatory Tcells. Like MZ B-cells, Breg mainly locate in the spleen
MZ where their survival and expansion are dependent on BAFF; In the fourth orientation, there is a novel complex of $\mathrm{CD} 21^{\text {lo }} \mathrm{B}$-cell subsets that include at least three different populations: activated memory B-cells $\left(\mathrm{CD} 21^{\mathrm{lo}} \mathrm{CD} 27^{+}\right)$, plasmablast precursors $\left(\mathrm{CD} 21^{\mathrm{lo}} \mathrm{CD} 27\right.$ ${ }^{\text {hi }} \mathrm{CD} 11 \mathrm{c}^{+} \mathrm{CD} 138^{+}$) and "exhausted" memory B-cells $\left(\mathrm{CD} 21^{\mathrm{lo}} \mathrm{CD} 27^{\mathrm{lo}} \mathrm{PD} 1{ }^{+} \mathrm{FCRL} 4^{+}\right)$. Increased numbers of these B-cell subsets in blood have been preferentially reported in aged mice and humans, and in patients with autoimmune diseases or during chronic viral infection. B-cells belonging to these subsets harbour a nonfunctional $\mathrm{BCR}$, and are frequently unresponsive to CD40L but strongly sensitive to TLR7 or TLR9 agonists. In healthy individuals, the latter $\mathrm{CD} 21^{\text {lo }}$ population would preferentially reside in mucosa-associated tissues, immediately beneath the epithelium, likely sampling invasive pathogens. The identification of these new B-cell subsets, whose functions and survival are highly dependent on signals outside of those targeted at BcR, particularly homing, highlights the previously unexpected complexity of the B-cell compartment. It is thus a novel challenge in immunology to decipher the respective influence of innate and adaptive signals on the outcome of the B-cell responses in healthy individuals, and also during aging, autoimmune diseases, and chronic viral infection. The increasingly complex roles of B-cells are not yet fully characterised, nor are the differences between murine models and the human system fully determined. Further characterisation of the remaining mysteries of B-cell compartmentalisation is of key importance to human pathology, both in the fields of autoimmune disorders and onco-haematology.

\section{Competing interests}

The authors declare no competing of interest with respect of this study neither do they have financial and commercial interests with the industry. Further, they have no conflict of interest of any type with any issue related with their 5 year past and present research.

\section{Authors' contributions}

$\mathrm{OG}$ and YR co-wrote the manuscript; FC and BP co-edited the manuscript; $\mathrm{GB}, \mathrm{GB}, \mathrm{FC}$ and SD contributed original data that inspired the manuscript, and drafted the illustrations. All authors read and approved the final manuscript.

\section{Author details}

${ }^{1}$ EA3064-GIMAP, Université de Lyon, Saint-Etienne, France. ${ }^{2}$ EFS Auvergne-Loire, Saint-Etienne, France. ${ }^{3}$ Vice-Rectorate for Graduate Studies and Research-Visiting Professor Program, King Saud University, Riyadh, Saud Arabia. ${ }^{4}$ INSERM U1016, Institut Cochin, Paris, France. ${ }^{5}$ CNRS UMR8104, Paris, France. ${ }^{6}$ Université Paris Descartes, Sorbonne Paris Cité, Paris, France.

${ }^{7}$ Zoology Department, Faculty of Science, Assiut University, 71516, Assiut, Egypt. ${ }^{8}$ Princes Johara Alibrahim Center for Cancer Research, Prostate Cancer Research Chair, College of Medicine, King Saud University, Riyadh, Saudi Arabia. 'Laboratoire de Microbiologie et Hygiène, CHU de Saint-Etienne, Saint-Etienne, France. ${ }^{10}$ Etablissement Français du Sang Auvergne-Loire, 42023, Saint-Etienne cedex 02, France.

Received: 25 July 2012 Accepted: 5 November 2012

Published: 29 November 2012 


\section{References}

1. Chaganti S, Heath EM, Bergler W, Kuo M, Buettner M, Niedobitek G, Rickinson AB, Bell Al: Epstein-Barr virus colonization of tonsillar and peripheral blood B-cell subsets in primary infection and persistence. Blood 2009, 113(25):6372-6381.

2. Zhu Y, Yao S, Chen L: Cell surface signaling molecules in the control of immune responses: a tide model. Immunity 2011, 34(4):466-478.

3. Al-Daccak R, Mooney N, Charron D: MHC class II signaling in antigenpresenting cells. Curr Opin Immunol 2004, 16(1):108-113.

4. Cognasse F, Payrat JM, Corash L, Osselaer JC, Garraud O: Platelet components associated with acute transfusion reactions: the role of platelet-derived soluble CD40 ligand. Blood 2008,

112(12):4779-4780

5. Zouali M: B lymphocytes-chief players and therapeutic targets in autoimmune diseases. Front Biosci 2008, 13:4852-4861.

6. Beutler BA: TLRs and innate immunity. Blood 2009, 113(7):1399-1407.

7. Bourke E, Bosisio D, Golay J, Polentarutti N, Mantovani A: The toll-like receptor repertoire of human $B$ lymphocytes: inducible and selective expression of TLR9 and TLR10 in normal and transformed cells. Blood 2003, 102(3):956-963.

8. Peng SL: Signaling in B cells via Toll-like receptors. Curr Opin Immunol 2005, 17(3):230-236.

9. Fillatreau S, Manz RA: Tolls for B cells. Eur J Immunol 2006, 36(4):798-801.

10. Cognasse F, Hamzeh-Cognasse H, Lafarge S, Chavarin P, Pozzetto B, Richard $Y$, Garraud O: Identification of two subpopulations of purified human blood B cells, CD27- CD23+ and CD27high CD80+, that strongly express cell surface Toll-like receptor 9 and secrete high levels of interleukin-6. Immunology 2008, 125(3):430-437.

11. Isnardi I, Ng YS, Menard L, Meyers G, Saadoun D, Srdanovic I, Samuels J, Berman J, Buckner JH, Cunningham-Rundles C, et al: Complement receptor 2/CD21- human naive $B$ cells contain mostly autoreactive unresponsive clones. Blood 2010, 115(24):5026-5036.

12. Richard $Y$, Amiel $C$, Jeantils V, Mestivier D, Portier A, Dhello G, Feuillard J, Creidy R, Nicolas JC, Raphael M: Changes in blood B cell phenotypes and Epstein-Barr virus load in chronically human immunodeficiency virusinfected patients before and after antiretroviral therapy. J Infect Dis 2010, 202(9):1424-1434.

13. Ng VL, McGrath MS: The immunology of AIDS-associated lymphomas. Immunol Rev 1998, 162:293-298.

14. Melchers F, Rolink AG, Schaniel C: The role of chemokines in regulating cell migration during humoral immune responses. Cell 1999, 99(4):351-354.

15. Bowman EP, Campbell JJ, Soler D, Dong Z, Manlongat N, Picarella D, Hardy RR, Butcher EC: Developmental switches in chemokine response profiles during B cell differentiation and maturation. J Exp Med 2000, 191(8):1303-1318.

16. Hargreaves DC, Hyman PL, Lu TT, Ngo VN, Bidgol A, Suzuki G, Zou YR, Littman DR, Cyster JG: A coordinated change in chemokine responsiveness guides plasma cell movements. J Exp Med 2001, 194(1):45-56.

17. Forster R, Mattis AE, Kremmer E, Wolf E, Brem G, Lipp M: A putative chemokine receptor, BLR1, directs B cell migration to defined lymphoid organs and specific anatomic compartments of the spleen. Cell 1996, 87(6):1037-1047.

18. Krzysiek R, Lefevre EA, Bernard J, Foussat A, Galanaud P, Louache F, Richard $Y$ : Regulation of CCR6 chemokine receptor expression and responsiveness to macrophage inflammatory protein-3alpha/CCL20 in human B cells. Blood 2000, 96(7):2338-2345.

19. Lamm ME, Phillips-Quagliata JM: Origin and homing of intestinal IgA antibody-secreting cells. J Exp Med 2002, 195(2):F5-8.

20. Lazarus NH, Kunkel EJ, Johnston B, Wilson E, Youngman KR, Butcher EC: A common mucosal chemokine (mucosae-associated epithelial chemokine/CCL28) selectively attracts IgA plasmablasts. J Immunol 2003, 170(7):3799-3805.

21. Casamayor-Palleja M, Mondiere P, Amara A, Bella C, Dieu-Nosjean MC, Caux C, Defrance $T$ : Expression of macrophage inflammatory protein-3alpha, stromal cell-derived factor-1, and B-cell-attracting chemokine-1 identifies the tonsil crypt as an attractive site for B cells. Blood 2001, 97(12):3992-3994.

22. McDonnell M, Liang Y, Noronha A, Coukos J, Kasper DL, Farraye FA, GanleyLeal LM: Systemic Toll-like receptor ligands modify B-cell responses in human inflammatory bowel disease. Inflamm Bowel Dis 2011, 17(1):298-307.
23. Liang $Y$, Hasturk H, Elliot J, Noronha A, Liu X, Wetzler LM, Massari P, Kantarci A, Winter HS, Farraye FA, et al: Toll-like receptor 2 induces mucosal homing receptor expression and IgA production by human B cells. Clin Immunol 2011, 138(1):33-40.

24. Viau M, Longo NS, Lipsky PE, Zouali M: Staphylococcal protein a deletes B-1a and marginal zone B lymphocytes expressing human immunoglobulins: an immune evasion mechanism. J Immunol 2005, 175(11):7719-7727.

25. Kearney JF: B cell subpopulations and secondary lymphoid organ architecture. Semin Immunol 2008, 20(1):1-3.

26. Hsu MC, Toellner KM, Vinuesa CG, Maclennan IC: B cell clones that sustain long-term plasmablast growth in T-independent extrafollicular antibody responses. Proc Natl Acad Sci USA 2006, 103(15):5905-5910

27. Kraal G: Cells in the marginal zone of the spleen. Int Rev Cytol 1992, 132:31-74.

28. Koike R, Nishimura T, Yasumizu R, Tanaka H, Hataba Y, Hataba Y, Watanabe $\mathrm{T}$, Miyawaki S, Miyasaka M: The splenic marginal zone is absent in alymphoplastic aly mutant mice. Eur J Immunol 1996, 26(3):669-675.

29. Nolte MA, Arens R, Kraus M, van Oers MH, Kraal G, van Lier RA, Mebius RE: B cells are crucial for both development and maintenance of the splenic marginal zone. J Immunol 2004, 172(6):3620-3627.

30. Backer R, Schwandt T, Greuter M, Oosting M, Jungerkes F, Tuting T, Boon L, O'Toole T, Kraal G, Limmer A, et al: Effective collaboration between marginal metallophilic macrophages and CD8+ dendritic cells in the generation of cytotoxic T cells. Proc Natl Acad Sci USA 2011, 107(1):216-221.

31. Odermatt B, Eppler M, Leist TP, Hengartner H, Zinkernagel RM: Virustriggered acquired immunodeficiency by cytotoxic T-cell-dependent destruction of antigen-presenting cells and lymph follicle structure. Proc Natl Acad Sci USA 1991, 88(18):8252-8256.

32. Aichele P, Zinke J, Grode L, Schwendener RA, Kaufmann SH, Seiler P: Macrophages of the splenic marginal zone are essential for trapping of blood-borne particulate antigen but dispensable for induction of specific T cell responses. J Immunol 2003, 171(3):1148-1155.

33. Yokota T, Ehlin-Henriksson B, Hansson GK: Scavenger receptors mediate adhesion of activated B lymphocytes. Exp Cell Res 1998, 239(1):16-22.

34. Chen Y, Pikkarainen T, Elomaa O, Soininen R, Kodama T, Kraal G, Tryggvason $K$ : Defective microarchitecture of the spleen marginal zone and impaired response to a thymus-independent type 2 antigen in mice lacking scavenger receptors MARCO and SR-A. I Immunol 2005, 175(12):8173-8180

35. You Y, Myers RC, Freeberg L, Foote J, Kearney JF, Justement LB, Carter RH: Marginal zone $B$ cells regulate antigen capture by marginal zone macrophages. J Immunol 2011, 186(4):2172-2181.

36. Koppel EA, Litjens M, van den Berg VC, van Kooyk Y, Geijtenbeek TB: Interaction of SIGNR1 expressed by marginal zone macrophages with marginal zone B cells is essential to early IgM responses against Streptococcus pneumoniae. Mol Immunol 2008, 45(10):2881-2887.

37. You Y, Zhao H, Wang Y, Carter RH: Cutting edge: Primary and secondary effects of CD19 deficiency on cells of the marginal zone. J Immunol 2009, 182(12):7343-7347.

38. Eloranta ML, Alm GV: Splenic marginal metallophilic macrophages and marginal zone macrophages are the major interferon-alpha/beta producers in mice upon intravenous challenge with herpes simplex virus. Scand J Immunol 1999, 49(4):391-394.

39. Louten J, van Rooijen N, Biron CA: Type 1 IFN deficiency in the absence of normal splenic architecture during lymphocytic choriomeningitis virus infection. J Immunol 2006, 177(5):3266-3272.

40. Montoya M, Schiavoni G, Mattei F, Gresser I, Belardelli F, Borrow P, Tough DF: Type I interferons produced by dendritic cells promote their phenotypic and functional activation. Blood 2002, 99(9):3263-3271.

41. Le Bon A, Etchart N, Rossmann C, Ashton M, Hou S, Gewert D, Borrow P, Tough DF: Cross-priming of CD8+ T cells stimulated by virus-induced type I interferon. Nat Immunol 2003, 4(10):1009-1015.

42. Timens $W$ : The human spleen and the immune system: not just another lymphoid organ. Res Immunol 1991, 142(4):316-320.

43. Timens W, Boes A, Vos H, Poppema S: Tissue distribution of the C3d/EBVreceptor: CD21 monoclonal antibodies reactive with a variety of epithelial cells, medullary thymocytes, and peripheral T-cells. Histochemistry 1991, 95(6):605-611. 
44. Steiniger B, Timphus EM, Barth PJ: The splenic marginal zone in humans and rodents: an enigmatic compartment and its inhabitants. Histochem Cell Biol 2006, 126(6):641-648

45. Steiniger B, Barth P, Herbst B, Hartnell A, Crocker PR: The species-specific structure of microanatomical compartments in the human spleen: strongly sialoadhesin-positive macrophages occur in the perifollicular zone, but not in the marginal zone. Immunology 1997, 92(2):307-316.

46. Steiniger B, Timphus EM, Jacob R, Barth PJ: CD27+ B cells in human lymphatic organs: re-evaluating the splenic marginal zone. Immunology 2005, 116(4):429-442.

47. Steiniger $B$, Barth $P$, Hellinger A: The perifollicular and marginal zones of the human splenic white pulp: do fibroblasts guide lymphocyte immigration? Am J Pathol 2001, 159(2):501-512.

48. Steiniger B, Stachniss V, Schwarzbach H, Barth PJ: Phenotypic differences between red pulp capillary and sinusoidal endothelia help localizing the open splenic circulation in humans. Histochem Cell Biol 2007, 128(5):391-398.

49. Pack M, Trumpfheller C, Thomas D, Park CG, Granelli-Piperno A, Munz C, Steinman RM: DEC-205/CD205+ dendritic cells are abundant in the white pulp of the human spleen, including the border region between the red and white pulp. Immunology 2008, 123(3):438-446.

50. Nascimbeni M, Perie L, Chorro L, Diocou S, Kreitmann L, Louis S, Garderet L, Fabiani B, Berger A, Schmitz J, et al: Plasmacytoid dendritic cells accumulate in spleens from chronically HIV-infected patients but barely participate in interferon-alpha expression. Blood 2009, 113(24):6112-6119.

51. Crowley MT, Reilly CR, Lo D: Influence of lymphocytes on the presence and organization of dendritic cell subsets in the spleen. J Immunol 1999, 163(9):4894-4900.

52. Birjandi SZ, Ippolito JA, Ramadorai AK, Witte PL: Alterations in marginal zone macrophages and marginal zone B cells in old mice. J Immunol 2011, 186(6):3441-3451.

53. Zindl CL, Kim TH, Zeng M, Archambault AS, Grayson MH, Choi K, Schreiber RD, Chaplin DD: The lymphotoxin LTalpha(1)beta(2) controls postnatal and adult spleen marginal sinus vascular structure and function. Immunity 2009, 30(3):408-420.

54. Moseman EA, lannacone M, Bosurgi L, Tonti E, Chevrier N, Tumanov A, Fu YX, Hacohen N, von Andrian UH: B cell maintenance of subcapsular sinus macrophages protects against a fatal viral infection independent of adaptive immunity. Immunity 2012, 36(3):415-426.

55. Lu TT, Cyster JG: Integrin-mediated long-term B cell retention in the splenic marginal zone. Science 2002, 297(5580):409-412.

56. Cinamon G, Zachariah MA, Lam OM, Foss FW Jr, Cyster JG: Follicular shuttling of marginal zone B cells facilitates antigen transport. Nat Immunol 2008, 9(1):54-62.

57. Ato M, Nakano H, Kakiuchi T, Kaye PM: Localization of marginal zone macrophages is regulated by C-C chemokine ligands 21/19. J Immunol 2004, 173(8):4815-4820.

58. Girkontaite I, Sakk V, Wagner M, Borggrefe T, Tedford K, Chun J, Fischer KD: The sphingosine-1-phosphate (S1P) lysophospholipid receptor S1P3 regulates MAdCAM-1+ endothelial cells in splenic marginal sinus organization. J Exp Med 2004, 200(11):1491-1501.

59. Cinamon G, Matloubian M, Lesneski MJ, Xu Y, Low C, Lu T, Proia RL, Cyster JG: Sphingosine 1-phosphate receptor 1 promotes B cell localization in the splenic marginal zone. Nat Immunol 2004, 5(7):713-720.

60. Engwerda CR, Ato M, Cotterell SE, Mynott TL, Tschannerl A, Gorak-Stolinska PM, Kaye PM: A role for tumor necrosis factor-alpha in remodeling the splenic marginal zone during Leishmania donovani infection. Am J Pathol 2002, 161(2):429-437.

61. Saito T, Chiba S, Ichikawa M, Kunisato A, Asai T, Shimizu K, Yamaguchi T, Yamamoto G, Seo S, Kumano K, et al: Notch2 is preferentially expressed in mature $B$ cells and indispensable for marginal zone $B$ lineage development. Immunity 2003, 18(5):675-685.

62. Hozumi K, Negishi N, Suzuki D, Abe N, Sotomaru Y, Tamaoki N, Mailhos C, Ish-Horowicz D, Habu S, Owen MJ: Delta-like 1 is necessary for the generation of marginal zone B cells but not T cells in vivo. Nat Immunol 2004, 5(6):638-644

63. Khan WN, Alt FW, Gerstein RM, Malynn BA, Larsson I, Rathbun G, Davidson L, Muller S, Kantor AB, Herzenberg LA, et al: Defective B cell development and function in Btk-deficient mice. Immunity 1995, 3(3):283-299.

64. Tanigaki K, Han H, Yamamoto N, Tashiro K, Ikegawa M, Kuroda K, Suzuki A, Nakano T, Honjo T: Notch-RBP-J signaling is involved in cell fate determination of marginal zone B cells. Nat Immunol 2002, 3(5):443-450.
65. Loder F, Mutschler B, Ray RJ, Paige CJ, Sideras P, Torres R, Lamers MC, Carsetti R: B cell development in the spleen takes place in discrete steps and is determined by the quality of B cell receptor-derived signals. J Exp Med 1999, 190(1):75-89.

66. Pillai S, Cariappa A: The follicular versus marginal zone B lymphocyte cell fate decision. Nat Rev Immunol 2009, 9(11):767-777.

67. Dunn-Walters DK, Isaacson PG, Spencer J: Analysis of mutations in immunoglobulin heavy chain variable region genes of microdissected marginal zone (MGZ) B cells suggests that the MGZ of human spleen is a reservoir of memory B cells. J Exp Med 1995, 182(2):559-566.

68. Tangye SG, Liu YJ, Aversa G, Phillips JH, de Vries JE: Identification of functional human splenic memory B cells by expression of CD148 and CD27. J Exp Med 1998, 188(9):1691-1703.

69. Weller S, Braun MC, Tan BK, Rosenwald A, Cordier C, Conley ME, Plebani A, Kumararatne DS, Bonnet D, Tournilhac O, et al: Human blood IgM "memory" B cells are circulating splenic marginal zone $B$ cells harboring a prediversified immunoglobulin repertoire. Blood 2004, 104(12):3647-3654.

70. Rosner K, Winter DB, Tarone RE, Skovgaard GL, Bohr VA, Gearhart PJ: Third complementarity-determining region of mutated $\mathrm{VH}$ immunoglobulin genes contains shorter $\mathrm{V}, \mathrm{D}, \mathrm{J}, \mathrm{P}$, and $\mathrm{N}$ components than non-mutated genes. Immunology 2001, 103(2):179-187.

71. Weller S, Mamani-Matsuda M, Picard C, Cordier C, Lecoeuche D, Gauthier F, Weill JC, Reynaud CA: Somatic diversification in the absence of antigendriven responses is the hallmark of the $\lg M+\lg D+C D 27+B$ cell repertoire in infants. J Exp Med 2008, 205(6):1331-1342.

72. Weill J, Weller S, Reynaud C: Human Marginal Zone B cells. Annu Rev Immunol 2009, 27:267-285.

73. Litinskiy MB, Nardelli B, Hilbert DM, He B, Schaffer A, Casali P, Cerutti A: DCs induce CD40-independent immunoglobulin class switching through BLyS and APRIL. Nat Immunol 2002, 3(9):822-829.

74. Willenbrock K, Jungnickel B, Hansmann ML, Kuppers R: Human splenic marginal zone $B$ cells lack expression of activation-induced cytidine deaminase. Eur J Immunol 2005, 35(10):3002-3007.

75. Mackay F, Browning JL: BAFF: a fundamental survival factor for B cells. Nat Rev Immunol 2002, 2(7):465-475.

76. Lavie F, Miceli-Richard C, Quillard J, Roux S, Leclerc P, Mariette X: Expression of BAFF (BLyS) in T cells infiltrating labial salivary glands from patients with Sjogren's syndrome. J Pathol 2004, 202(4):496-502.

77. Mariette X, Roux S, Zhang J, Bengoufa D, Lavie F, Zhou T, Kimberly R: The level of BLyS (BAFF) correlates with the titre of autoantibodies in human Sjogren's syndrome. Ann Rheum Dis 2003, 62(2):168-171.

78. Fletcher CA, Sutherland AP, Groom JR, Batten ML, Ng LG, Gommerman J Mackay F: Development of nephritis but not sialadenitis in autoimmune-prone BAFF transgenic mice lacking marginal zone $B$ cells. Eur J Immunol 2006, 36(9):2504-2514.

79. Ittah M, Miceli-Richard C, Gottenberg JE, Sellam J, Eid P, Lebon P, Pallier C, Lepajolec C, Mariette X: Viruses induce high expression of BAFF by salivary gland epithelial cells through TLR- and type-I IFN-dependent and -independent pathways. Eur J Immunol 2008, 38(4):1058-1064.

80. Ittah M, Miceli-Richard C, Lebon P, Pallier C, Lepajolec C, Mariette X: Induction of $B$ cell-activating factor by viral infection is a general phenomenon, but the types of viruses and mechanisms depend on cell type. J Innate Immun 2011, 3(2):200-207.

81. Chaoul N, Burelout C, Peruchon S, van Buu BN, Laurent P, Proust A, Raphael M, Garraud O, Le Grand R, Prevot S, et al: Default in plasma and intestinal $\lg \mathrm{A}$ responses during acute infection by simian immunodeficiency virus. Retrovirology 2012, 9:43.

82. Peruchon $S$, Chaoul N, Burelout $C$, Delache $B$, Brochard $P$, Laurent $P$, Cognasse F, Prevot S, Garraud O, Le Grand R, et al: Tissue-specific B-cell dysfunction and generalized memory B-cell loss during acute SIV infection. PLoS One 2009, 4(6):e5966.

83. Ferguson AR, Youd ME, Corley RB: Marginal zone B cells transport and deposit lgM-containing immune complexes onto follicular dendritic cells. Int Immuno/ 2004, 16(10):1411-1422.

84. Shiow LR, Rosen DB, Brdickova N, Xu Y, An J, Lanier LL, Cyster JG, Matloubian M: CD69 acts downstream of interferon-alpha/beta to inhibit S1P1 and lymphocyte egress from lymphoid organs. Nature 2006, 440(7083):540-544.

85. Chang WL, Coro ES, Rau FC, Xiao Y, Erle DJ, Baumgarth N: Influenza virus infection causes global respiratory tract $B$ cell response modulation via innate immune signals. J Immunol 2007, 178(3):1457-1467. 
86. Badr G, Borhis G, Lefevre EA, Chaoul N, Deshayes F, Dessirier V, Lapree G, Tsapis A, Richard Y: BAFF enhances chemotaxis of primary human B cells: a particular synergy between BAFF and CXCL13 on memory B cells. Blood 2008, 111(5):2744-2754.

87. Zandvoort A, Lodewijk ME, de Boer NK, Dammers PM, Kroese FG, Timens W: CD27 expression in the human splenic marginal zone: the infant marginal zone is populated by naive B cells. Tissue Antigens 2001, 58(4):234-242.

88. Timens W, Boes A, Rozeboom-Uiterwijk T, Poppema S: Immaturity of the human splenic marginal zone in infancy. Possible contribution to the deficient infant immune response. J Immunol 1989, 143(10):3200-3206.

89. Delia D, Cattoretti G, Polli N, Fontanella E, Aiello A, Giardini R, Rilke F, Della Porta G: CD1c but neither CD1a nor CD1b molecules are expressed on normal, activated, and malignant human $B$ cells: identification of a new B-cell subset. Blood 1988, 72(1):241-247.

90. Overturf GD: Pneumococcal vaccination of children. Semin Pediatr Infect Dis 2002, 13(3):155-164.

91. Giebink GS: The prevention of pneumococcal disease in children. N Engl J Med 2001, 345(16):1177-1183.

92. Puga I, Cols M, Barra CM, He B, Cassis L, Gentile M, Comerma L, Chorny A Shan $M, X u$ W, et al: B cell-helper neutrophils stimulate the diversification and production of immunoglobulin in the marginal zone of the spleen. Nat Immunol 2012, 13(2):170-180.

93. Artz AS, Ershler WB, Longo DL: Pneumococcal vaccination and revaccination of older adults. Clin Microbiol Rev 2003, 16(2):308-318.

94. Shi Y, Yamazaki T, Okubo Y, Uehara Y, Sugane K, Agematsu K: Regulation of aged humoral immune defense against pneumococcal bacteria by $\lg \mathrm{M}$ memory B cell. J Immunol 2005, 175(5):3262-3267.

95. Di Sabatino A, Carsetti R, Corazza GR: Post-splenectomy and hyposplenic states. Lancet 2011, 378(9785):86-97.

96. Carsetti R, Rosado MM, Wardmann H: Peripheral development of B cells in mouse and man. Immunol Rev 2004, 197:179-191.

97. Carsetti R: Characterization of B-cell maturation in the peripheral immune system. Methods Mol Biol 2004, 271:25-35.

98. Wong WY, Powars DR, Chan L, Hiti A, Johnson C, Overturf G: Polysaccharide encapsulated bacterial infection in sickle cell anemia: a thirty year epidemiologic experience. Am J Hematol 1992, 39(3):176-182.

99. Di Sabatino A, Rosado MM, Ciccocioppo R, Cazzola P, Morera R, Corazza GR, Carsetti R: Depletion of immunoglobulin M memory B cells is associated with splenic hypofunction in inflammatory bowel disease. Am J Gastroenterol 2005, 100(8):1788-1795.

100. Di Sabatino A, Rosado MM, Miele L, Capolunghi F, Cazzola P, Biancheri P, Carsetti R, Gasbarrini G, Corazza GR: Impairment of splenic IgM-memory but not switched-memory B cells in a patient with celiac disease and splenic atrophy. J Allergy Clin Immunol 2007, 120(6):1461-1463.

101. Spencer J, Finn T, Isaacson PG: Gut associated lymphoid tissue: a morphological and immunocytochemical study of the human appendix. Gut 1985, 26(7):672-679.

102. Spencer J: Differentiating ulcerative colitis from Crohn's disease: false dawn for CD44. Gut 1998, 43(3):310-311.

103. Spencer J, Perry ME, Dunn-Walters DK: Human marginal-zone B cells. Immunol Today 1998, 19(9):421-426.

104. Dono M, Zupo S, Leanza N, Melioli G, Fogli M, Melagrana A, Chiorazzi N, Ferrarini M: Heterogeneity of tonsillar subepithelial B lymphocytes, the splenic marginal zone equivalents. J Immunol 2000, 164(11):5596-5604.

105. Kawai T, Akira S: The role of pattern-recognition receptors in innate immunity: update on Toll-like receptors. Nat Immunol 2010, 11(5):373-384.

106. Chiron D, Bekeredjian-Ding I, Pellat-Deceunynck C, Bataille R, Jego G: Toll-like receptors: lessons to learn from normal and malignant human $B$ cells. Blood 2008, 112(6):2205-2213

107. Xu W, Santini PA, Matthews AJ, Chiu A, Plebani A, He B, Chen K, Cerutti A: Viral double-stranded RNA triggers Ig class switching by activating upper respiratory mucosa $B$ cells through an innate TLR3 pathway involving BAFF. J Immunol 2008, 181(1):276-287.

108. Wetzler LM: The role of Toll-like receptor 2 in microbial disease and immunity. Vaccine 2003, 21(Suppl 2):S55-60.

109. Bekeredjian-Ding I, Inamura S, Giese T, Moll H, Endres S, Sing A, Zahringer U, Hartmann G: Staphylococcus aureus protein A triggers T cellindependent B cell proliferation by sensitizing B cells for TLR2 ligands. J Immunol 2007, 178(5):2803-2812.
110. Cognasse F, Hamzeh H, Chavarin P, Acquart S, Genin C, Garraud O Evidence of Toll-like receptor molecules on human platelets. Immunol Cell Biol 2005, 83(2):196-198.

111. Park B, Brinkmann MM, Spooner E, Lee CC, Kim YM, Ploegh HL: Proteolytic cleavage in an endolysosomal compartment is required for activation of Toll-like receptor 9. Nat Immunol 2008, 9(12):1407-1414.

112. Chaturvedi A, Dorward D, Pierce SK: The B cell receptor governs the subcellular location of Toll-like receptor 9 leading to hyperresponses to DNA-containing antigens. Immunity 2008, 28(6):799-809.

113. Bernasconi NL, Onai N, Lanzavecchia A: A role for Toll-like receptors in acquired immunity: up-regulation of TLR9 by $B C R$ triggering in naive $B$ cells and constitutive expression in memory B cells. Blood 2003, 101(11):4500-4504.

114. Jiang W, Lederman MM, Harding CV, Rodriguez B, Mohner RJ, Sieg SF: TLR9 stimulation drives naive $B$ cells to proliferate and to attain enhanced antigen presenting function. Eur J Immunol 2007, 37(8):2205-2213.

115. Bekeredjian-Ding IB, Wagner M, Hornung V, Giese T, Schnurr M, Endres S, Hartmann G: Plasmacytoid dendritic cells control TLR7 sensitivity of naive B cells via type I IFN. J Immunol 2005, 174(7):4043-4050.

116. Barral P, Eckl-Dorna J, Harwood NE, De Santo C, Salio M, Illarionov P, Besra GS, Cerundolo V, Batista FD: B cell receptor-mediated uptake of CD1drestricted antigen augments antibody responses by recruiting invariant NKT cell help in vivo. Proc Natl Acad Sci USA 2008, 105(24):8345-8350.

117. Lang GA, Illarionov PA, Glatman-Freedman A, Besra GS, Lang ML: BCR targeting of biotin-\{alpha\}-galactosylceramide leads to enhanced presentation on CD1d and requires transport of BCR to CD1d-containing endocytic compartments. Int Immunol 2005, 17(7):899-908.

118. Allan LL, Stax AM, Zheng DJ, Chung BK, Kozak FK, Tan R, van den Elzen P: CD1d and CD1c expression in human B cells is regulated by activation and retinoic acid receptor signaling. J Immunol 2011, 186(9):5261-5272

119. Leadbetter EA, Brigl M, Illarionov P, Cohen N, Luteran MC, Pillai S, Besra GS, Brenner MB: NK T cells provide lipid antigen-specific cognate help for B cells. Proc Natl Acad Sci USA 2008, 105(24):8339-8344

120. Allan LL, Hoefl K, Zheng DJ, Chung BK, Kozak FK, Tan R, van den Elzen P: Apolipoprotein-mediated lipid antigen presentation in $\mathrm{B}$ cells provides a pathway for innate help by NKT cells. Blood 2009, 114(12):2411-2416.

121. Bialecki E, Paget C, Fontaine J, Capron M, Trottein F, Faveeuw C: Role of marginal zone B lymphocytes in invariant NKT cell activation. J Immunol 2009, 182(10):6105-6113.

122. Bosma A, Abdel-Gadir A, Isenberg DA, Jury EC, Mauri C: Lipid-antigen presentation by $\mathrm{CD} 1 \mathrm{~d}(+) \mathrm{B}$ cells is essential for the maintenance of invariant natural killer T cells. Immunity 2012, 36(3):477-490.

123. Mauri $C$, Ehrenstein MR: The 'short' history of regulatory B cells. Trends Immunol 2008, 29(1):34-40

124. Fillatreau S, Gray D, Anderton SM: Not always the bad guys: B cells as regulators of autoimmune pathology. Nat Rev Immunol 2008, 8(5):391-397.

125. Bouaziz JD, Yanaba K, Tedder TF: Regulatory B cells as inhibitors of immune responses and inflammation. Immunol Rev 2008, 224:201-214.

126. Yanaba K, Bouaziz JD, Haas KM, Poe JC, Fujimoto M, Tedder TF: A regulatory $B$ cell subset with a unique $C D 1 d$ hiCD5+ phenotype controls T cell-dependent inflammatory responses. Immunity 2008, 28(5):639-650

127. Yanaba K, Bouaziz JD, Matsushita T, Magro CM, St Clair EW, Tedder TF: B-lymphocyte contributions to human autoimmune disease. Immunol Rev 2008, 223:284-299.

128. Watanabe R, Ishiura N, Nakashima H, Kuwano Y, Okochi H, Tamaki K, Sato S, Tedder TF, Fujimoto M: Regulatory B cells (B10 cells) have a suppressive role in murine lupus: CD19 and B10 cell deficiency exacerbates systemic autoimmunity. J Immunol 2011, 184(9):4801-4809.

129. Ding Q, Yeung M, Camirand G, Zeng Q, Akiba H, Yagita H, Chalasani G, Sayegh MH, Najafian N, Rothstein DM: Regulatory B cells are identified by expression of TIM-1 and can be induced through TIM-1 ligation to promote tolerance in mice. J Clin Invest 2011, 121(9):3645-3656.

130. Yang $M$, Sun L, Wang S, Ko KH, Xu H, Zheng BJ, Cao X, Lu L: Novel function of $B$ cell-activating factor in the induction of IL-10-producing regulatory B cells. J Immunol 2010, 184(7):3321-3325.

131. Lund FE, Randall TD: Effector and regulatory B cells: modulators of CD4(+) T cell immunity. Nat Rev Immunol, 10(4):236-247. 
132. Bouaziz JD, Calbo S, Maho-Vaillant M, Saussine A, Bagot M, Bensussan A, Musette P: IL-10 produced by activated human B cells regulates CD4(+) T-cell activation in vitro. Eur J Immunol 2010, 40(10):2686-2691.

133. Iwata Y, Matsushita T, Horikawa M, Dilillo DJ, Yanaba K, Venturi GM, Szaboles PM, Bernstein SH, Magro CM, Williams AD, et al: Characterization of a rare IL-10-competent B-cell subset in humans that parallels mouse regulatory B10 cells. Blood 2011, 117(2):530-541.

134. Blair PA, Norena LY, Flores-Borja F, Rawlings DJ, Isenberg DA, Ehrenstein MR, Mauri C: CD19(+)CD24(hi)CD38(hi) B cells exhibit regulatory capacity in healthy individuals but are functionally impaired in systemic Lupus Erythematosus patients. Immunity, 32(1):129-140.

135. Zouali M, Richard Y: Marginal zone B-cells, a gatekeeper of innate immunity. Front Immunol 2011, 2:63.

136. Hartung HP, Kieseier BC: Atacicept: targeting B cells in multiple sclerosis. Ther Adv Neurol Disord 2010, 3(4):205-216.

137. Griffin DO, Rothstein TL: Human "orchestrator" CD11b(+) B1 cells spontaneously secrete IL-10 and regulate T cell activity. Mol Med 2012.

138. Hao Y, O'Neill P, Naradikian MS, Scholz JL, Cancro MP: A B-cell subset uniquely responsive to innate stimuli accumulates in aged mice. Blood 2011, 118(5):1294-1304

139. Linterman MA, Vinuesa CG: Signals that influence $T$ follicular helper cell differentiation and function. Semin Immunopathol 2010, 32(2):183-196.

140. Rubtsov AV, Rubtsova K, Fischer A, Meehan RT, Gillis JZ, Kappler JW, Marrack $P$ : Toll-like receptor 7 (TLR7)-driven accumulation of a novel CD11C(+) B-cell population is important for the development of autoimmunity. Blood 2011, 118(5):1305-1315.

141. Warnatz K, Wehr C, Drager R, Schmidt S, Eibel H, Schlesier M, Peter HH: Expansion of CD19(hi)CD21(lo/neg) B cells in common variable immunodeficiency (CVID) patients with autoimmune cytopenia. Immunobiology 2002, 206(5):502-513.

142. Ehrhardt GR, Hsu JT, Gartland L, Leu CM, Zhang S, Davis RS, Cooper MD: Expression of the immunoregulatory molecule FcRH4 defines a distinctive tissue-based population of memory B cells. J Exp Med 2005, 202(6):783-791.

143. Falini B, Tiacci E, Pucciarini A, Bigerna B, Kurth J, Hatzivassiliou G, Droetto S, Galletti BV, Gambacorta M, Orazi A, et al: Expression of the IRTA1 receptor identifies intraepithelial and subepithelial marginal zone B cells of the mucosa-associated lymphoid tissue (MALT). Blood 2003, 102(10):3684-3692.

144. Ehrhardt GR, Hijikata A, Kitamura H, Ohara O, Wang JY, Cooper MD: Discriminating gene expression profiles of memory $B$ cell subpopulations. J Exp Med 2008, 205(8):1807-1817.

145. Weiss GE, Crompton PD, Li S, Walsh LA, Moir S, Traore B, Kayentao K, Ongoiba A, Doumbo OK, Pierce SK: Atypical memory B cells are greatly expanded in individuals living in a malaria-endemic area. $J$ Immunol 2009, 183(3):2176-2182.

146. Rakhmanov M, Gutenberger S, Keller B, Schlesier M, Peter HH, Warnatz K: CD21low B cells in common variable immunodeficiency do not show defects in receptor editing, but resemble tissue-like memory $B$ cells. Blood 2010, 116(18):3682-3683.

147. Sohn HW, Krueger PD, Davis RS, Pierce SK: FcRL4 acts as an adaptive to innate molecular switch dampening BCR signaling and enhancing TLR signaling. Blood 2011, 118(24):6332-6341.

148. Moir S, Ho J, Malaspina A, Wang W, DiPoto AC, O'Shea MA, Roby G, Kottilil S, Arthos J, Proschan MA, et al: Evidence for HIV-associated B cell exhaustion in a dysfunctional memory $B$ cell compartment in HIV-infected viremic individuals. J Exp Med 2008, 205(8):1797-1805.

149. Kardava L, Moir S, Wang W, Ho J, Buckner CM, Posada JG, O'Shea MA, Roby G, Chen J, Sohn HW, et al: Attenuation of HIV-associated human B cell exhaustion by siRNA downregulation of inhibitory receptors. J Clin Invest 2011, 121(7):2614-2624.

150. Titanji K, Velu V, Chennareddi L, Vijay-Kumar M, Gewirtz AT, Freeman GJ, Amara RR: Acute depletion of activated memory B cells involves the PD-1 pathway in rapidly progressing SIV-infected macaques. J Clin Invest 2010, 120(11):3878-3890.

\section{doi:10.1186/1471-2172-13-63}

Cite this article as: Garraud et al:: Revisiting the B-cell compartment in mouse and humans: more than one B-cell subset exists in the marginal zone and beyond. BMC Immunology 2012 13:63.

\section{Submit your next manuscript to BioMed Central and take full advantage of:}

- Convenient online submission

- Thorough peer review

- No space constraints or color figure charges

- Immediate publication on acceptance

- Inclusion in PubMed, CAS, Scopus and Google Scholar

- Research which is freely available for redistribution 